\title{
التحديّات المستقبليّة المترتبة على استخدام التعلّم الإلكتروني في التدريس الجامعيّ
}

\author{
نـرجـــ عبـد القـادر حهـدي \\ أستاذ دكتور- قسم المناهج والتدريس- كلية العلوم التربوية- الجامعة الأردنية- الأردن \\ narjeshamdi@yahoo.com
}




\title{
التحديّّات المستقبليّة المترتبة على استخدام التعلّم الإلكتروني في التدريس الجامعيّ
}

\author{
نرجس عبد القادرحمـدي \\ أستاذ دكتور - قسم المناهج والتدريس- كلية العلوم التربوية- الجامعة الأردنية- الأردن \\ narjeshamdi@yahoo.com
}

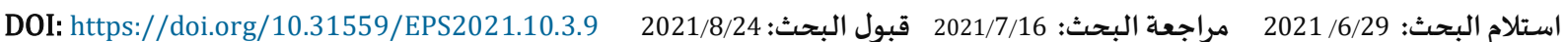

هذه الدراسة قدمت وصفًا وتحلياً لآراء عينة مختارة من الخبراء والطلبة الجامعيين، تناول أبرز التحديّات المستقبلية المترتبة على

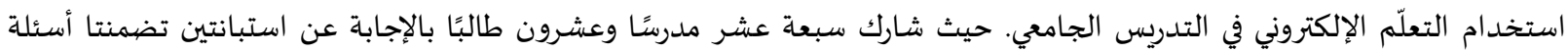

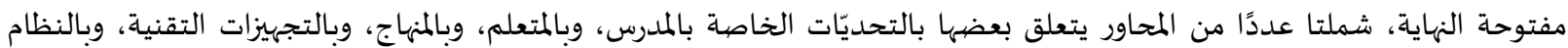

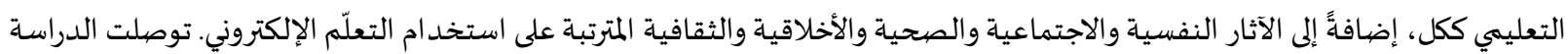
إلى النتائج التالية: بالنسبة للمدرسين؛ جاء في المراتب الأولى: قلة الوعي بالمفهوم، وضعف التدريب التهاريه على التجهيزات التقنية بنسبة (65\%)،

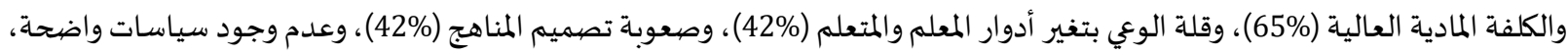

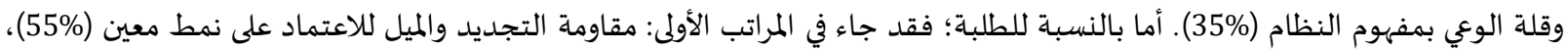
وضعف المهارات في التعامل مع التجهيزات (55\%)، والتعلم الذاتي وتغيّر الأدوار (40\%). وقد أشار كلا الطرفين إلى عدد من الآثار النفسية معائ

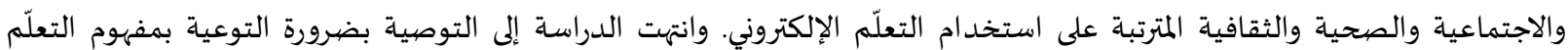
الإلكتروني باعتباره نظامًا متكاملً، وإجراء المزيد من الدراسات الهادفة إلى رسم الخطط اللازمة لبناء استراتيجيات حديثة في مواجهة تلك

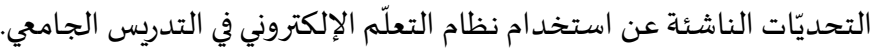
الكلمات المفتاحية: التعلّم الإلكتروني؛ التحديّات المستقبلية؛ التدريس الجامعي.

إنّ مصير الأمم رهن بإبداع أبنائها وبمدى تقبلهم واستعداداتهم لمشكلات التغيّر وتحديّاته. وتعتبر التربية من أهم الأركان التي شملتها رياح التغيّر والتجديد، حيث يحتل التعلّم والتعليم موقعًا بارزًا ضمن إطار النقلة المجتمعية التي يحدثها التعلّم الإلكتروني. ولأن هناك من ينظر إلى التعاك التعليم الجامعي

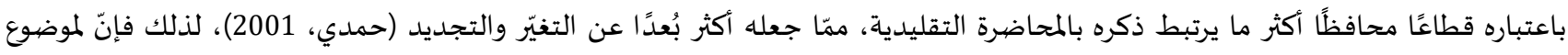
التحديّات المترتبة على استخدام التعلّم الإلكتروني في التدريس الجامعي، أهمية خاصة باعتباره أحد موضوعات الساعة التي تحتاج إلى المزيد من الدراسـة والبحث. يُنظر إلى التحدي باعتباره حالة أو ظروف غير ملائمة يشكّل بقاؤها تهديدًا لمنظومة القيم السائدة في المجتمع، ومن ثم وجب معرفتها وتحديدها

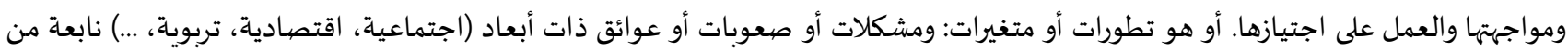

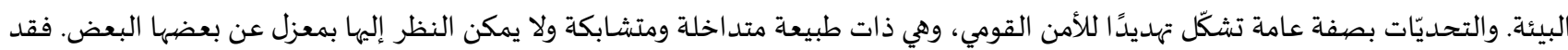
يكون التحدي سببًا في تحديّات أخرى، كما أن تأثيرها لا يقتصر على الآونة الراهنة بل يمتد إلى المستقبل، ومن هنا فهي تتطلب مزيدًا من الجهود الفكرية

" أُجري هذا البحث اثناء إجـازة التفرغ العلمي الممنـوحسة لي من قبل الجامعة الأردنية خلال العام الدراسي 2019/2018 
والعلمية لإعد اد استراتيجيات ملائمة لمواجهتها (سليمان، 2014). ونظرًا لتنامي تلك التحديّات فقد أضحت الحاجة ملحة للتعرف عليها وتحديدها أملاً

في وضع الاستراتيجيات المناسبة لمواجهتها والتصديدي لها. يتأثر التعليم العالي عامةً والتدريس الجامعي خاصيةً بعدد من العوامل والقوى المؤثرة التي تشكّل في مجملها تيار التجديد "عولمة التعليم"، ويتأثر

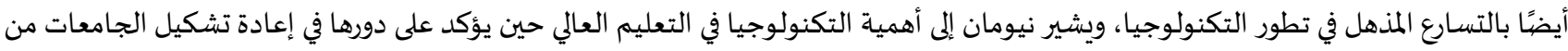

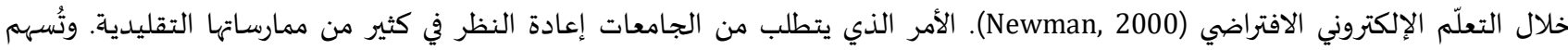

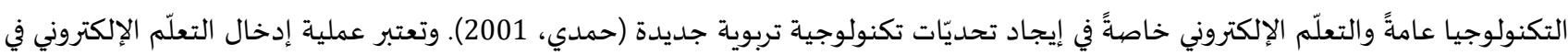

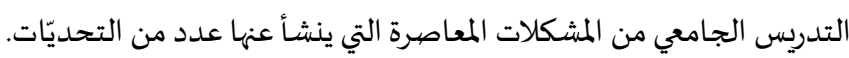

وقد واجهت الجامعات مهمة شاقة تتمثل في الاضطرار إلى إعادة ضبط نفسها وتنظيمها استعدادًا لدمج التعلّم الإلكتروني في مؤسساتها. كما

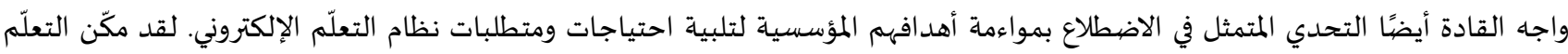
الإلكتروني الجامعات من التوسع في امتدادها الجغرافي الحالي، والاستفادة من الطلاب الجدد وتأسيس أنفسهم كمزودي خدمات تعليمية عالمية.

(Mapuva, 2009)

وعليه فإن بروز التعلّم الإلكتروني وانتشاره بالأوساط التربوية يجعل من السؤال التالي "ما التحديّات المستقبلية المترتبة على استخدام التعلّم

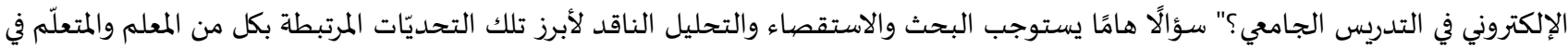
المجالات التالية: الوعي الثقافي لمفهوم التعلّم الإلكتروني، والدور الجديد لكل من المعلم والمتعلّم في نطاق التعلّم الإلكتروني، والتعامل مع المصادرد

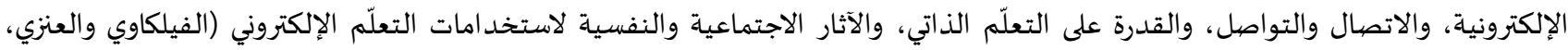

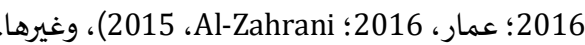

يُعرّف التعلّم الإلكتروني (E-learning) على أنهاه نظام متكامل يشمل كافة عناصر العملية التعلّمية التعليمية بمختلف جوانها، ويعتمد بيئة

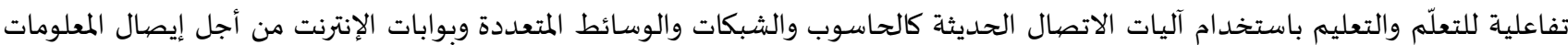

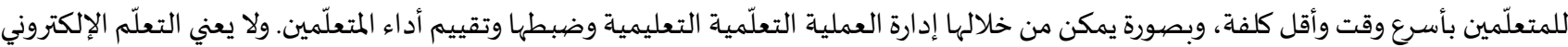
تحويل المحتوى إلى صفحة ويب أو قرص مدمج، بل هو تصميم المحتوى وتحويله إلى أنشطة الكترونية تفاعلية يكون المتعلّم فيها محور عملية التعلّم، وهو الباحث والمحلل للمعلومات، في حين يكون المدرس ميسرًا ومرشدًا للمتعلّم في تعلّمها الذاتي، أو من خلال مجموعة فئ، باستخدام التكنولوجيا الحديثة لأن التعلّم الإلكتروني نظام متكامل. كما يمتاز التعلّم الإلكتروني بكونه أسلوب من الأسـاليب التي تعتمد على تكنولوجيا المعلومات لتقديم المحتوى التعليمي وتنمية المفاهيم والمهارات

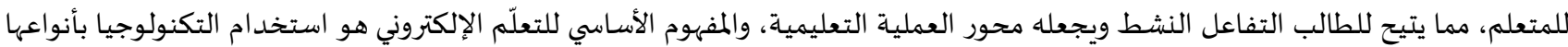

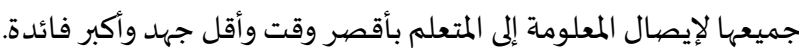

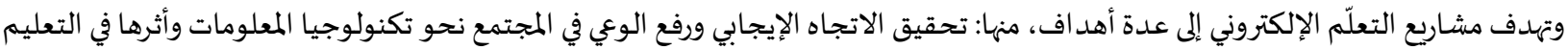

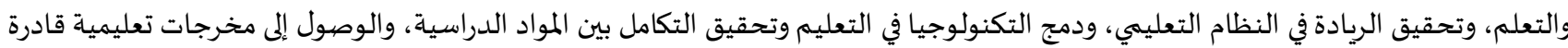

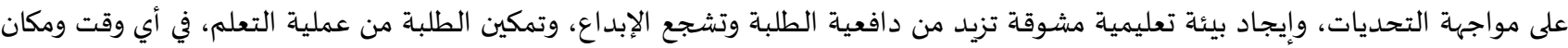

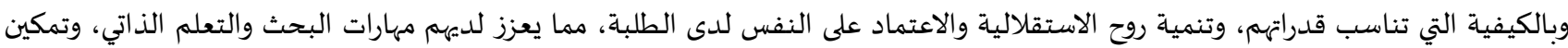
المعلم من أداء عمله بكفاءة وإبداع؛ وذلك بإتاحة طرائق تدريسية تشبع حاجات الطلبة وتوقعاتهم المتنوعة، وزيادة التواصل بين أطراف المنظومة

التعليمية. (السليتي، 2015) يتميز التعلّم الإلكتروني بميزات عدة، منها: التفاعل وسهولة الاتصال بين الطّلبة فيما بينهم، وبين الطّلبة والمدرسة في عدة اتجاهات مثل مجالس

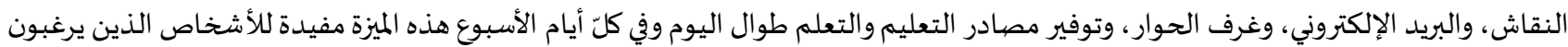
التعليم في وقت معين، وذلك لأنّ بعضهم يفضل التعلم صبباحًا، والآخر مساءً، كذلك للذين يتحملون أعباء ومسؤوليات شخصية، والتعدد والتنوع في

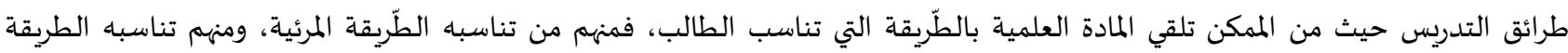

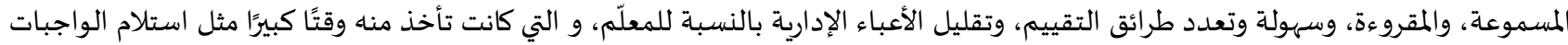

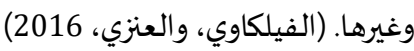
ولكي ينجح تطبيق التعلّم الإلكتروني فلا بد من توفير عدة متطلبات لدى المتعلمين، منها: مهارات استخدام الحاسوب والإنترنت، والتحفيز الذاتي للدراسة والتعلم، والقدرة على الدراسة المستقلة، والانضباط الذاتي في الدراسة والالتزام بالمواعيد والواجبات ومسؤوليات التعلم المختلفة، والقدرة

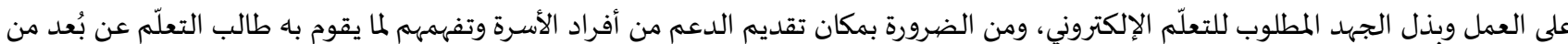
أهد اف ومسؤوليات ونتائج وتوفيرهم للوقت والظروف البيئية للوصول إلى التعلّم المنشود. (السليتي، 2015) 


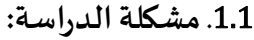

تتسابق الجامعات في الإعلان عن نفسها كمؤسسات تربوية تساير التطور وتلحق ركب التجديد، ولأن موضيوع التعلّم الإلكتروني أحد موضيوعات الساعة التي تعكس هذا التجديد، فقد لجأت العديد من الجامعات إلى تبني هذا النمط من التعلّم، فعملت على إنشاء المختبرات، وطوّرت شبكات وهات

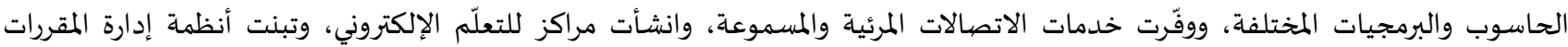

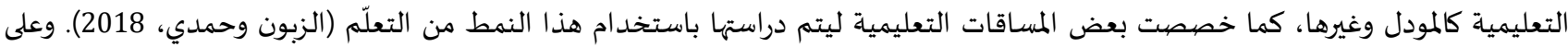

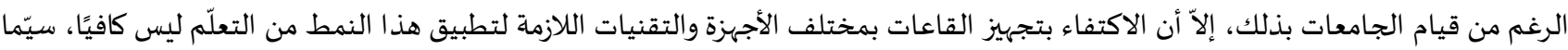

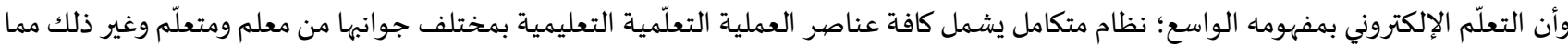

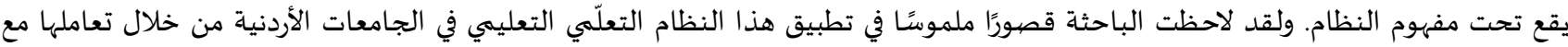
المدرسين والطلبة. ومن خلال ما تسمعاء من تعليقات المدرسين والطلبة حول هذا الموضوع، إضيافةً إلى ما طالعتاه من ادبيات سابقة تشير إلى ذلك الأمر.

(القضاة ومقابلة، 2013؛ العتيبي، 2016)

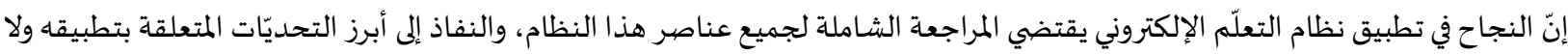
سيّما تلك التي تتعلق بالعنصبر البشري من معلمين ومتعلّمين. وعليه فإنّ في هذه الدراسـة محاولة للبحث في أبرز التحديّات المستقبلية المترتبة على استخد ام نظام التعلّم الإلكتروني في التدريس الجامعي.

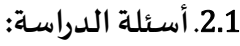

تسعى هذه الدراسة للإجابة عن السؤالين الآتيين:

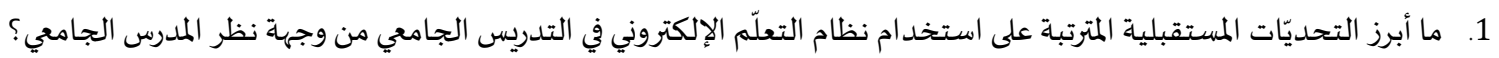

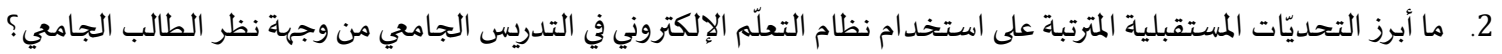

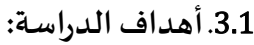

تهدف هذه الدراسـة إلى التوصل إلى أبرز التحديات المترتبة على استخدام نظام التعلّم الإلكتروني في التدريس الجامعي، وبشكل أكثر تحديدًا فهي

تهدف إلى:

1. التعرف إلى أبرز التحديّات المستقبلية المترتبة على استخدام نظام التعلّم الإلكتروني في التدريس الجامعي من وجهاة نظر المدرس الجامعي.

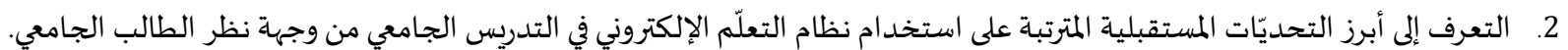

4.1 - 2.1 أهمية الدراسة:

تتخذ هذه الدراسة أهميتها من كونها تساير التطورات التكنولوجية التي تركز على استخدام التعلّم الإلكتروني في الميدان التربوي. ومن المتوقع لنتائج هذه الدراسـة أن تُسهم في التعرف إلى أبرز التحديّات المستقبلية المترتبة على استخدام التعلّم الإلكتروني في التـدريس الجامعي

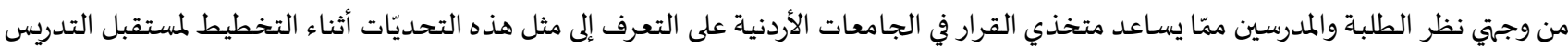

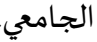
وتتجلّى أهمية الدراسة في كونها تنظر إلى التعلّم الإلكتروني باعتباره نظامًا تربويًا متكاملً، الأمر الذي ندر ظهوره في العديد من الدراسات السابقة، التي غالباً ما ركّزت على الجانب المتعلق بالتجهيزات التقنية في التعلّم الإلكتروني اثناء دراسـة هذا الموضونوع.

5.1

تتحدد نتائج هذه الدراسة بطبيعة العينة وأداة الدراسـة، حيث اقتصرت عينة الدراسة على عدد من مدرسي الجامعات العربية ذوي الخبرة في

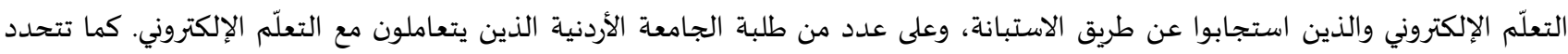
بتطبيقها خلال العام الجامعي (2019/2018)، كما تتحدد النتائج بطبيعة الأدوات المستخدمة في هذه الدراسة والمطوّرة من قبل الباحثة، حيث لمع لم يتيسر لها أداة قياس شاملة يمكن اعتمادها لهذه الجامي الغاية.

6.1.

فيما يلي عدد من المصطلحات التي وردت في الدراسة يمكن تعريفها على النحو التالي: •التعلّم الإلكتروني: نظام متكامل يشمل عملية التعلّم والتعليم بكافة عناصرها من معلم ومتعلّم ومنهاج، ويعتمد بُنية تفاعلية للتعلّم والتعليم باستخدام آليات الاتصال الحديثة كالحاسوب والشبكات والوسائط المتعددة وبوابات الإنترنت من أجل إيصال المعلومات للمتعلّمين بأسرع وقت فئم

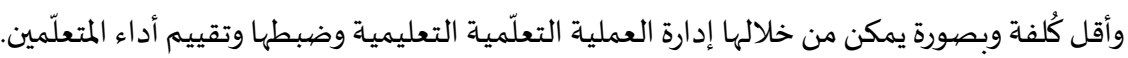




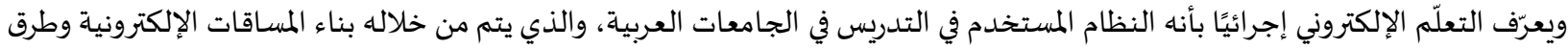

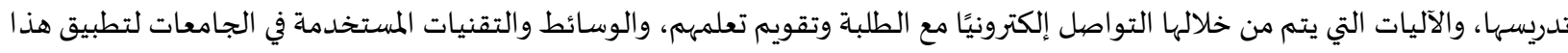
النظام. التحديّات المستقبلية: مجموعة العوامل الناتجة عن التجديدات التربوية والمتمثلة في انتشار التعلّم الإلكتروني وتطبيقه في التدريس الجامعي، والتي بدورها تشكّل تحديًا أمام المدرسين والمتعبلّمين.

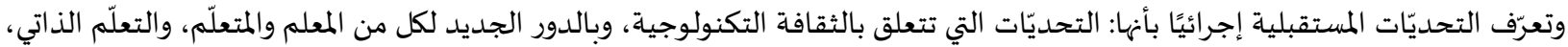

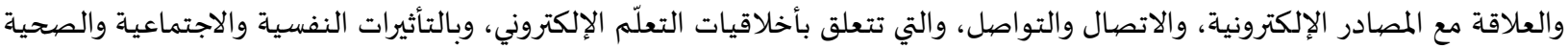
والثقافية والأخلاقية المترتبة على استخدام التعلّم الإلكتروني.

على الرغم من كثرة المصادر التي تناولت موضوع التعلّم الإلكتروني، إلاّ أنه ندرت الدراسات التي بحثت في التحديّات المترتبة على استخدام التعلّم الإلكتروني كنظام متكامل في التدريس الجامعي، وفيما يلي عرض لبعض الدراسات التي بحثت في الموضوع أو مسّت أجزاء منها: فـي دراسة أجرتها أندرسن (Andersson, 2008) حول أهم سبعة تحديّات تواجه التعلّم الإلكتروني في الدول النامية خصيّت فيها سيريلانكا

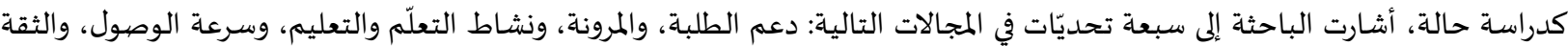
الأكاديمياة، والخصوصياة، والاتجاهات.

وفي دراسة أجراها مشهوروصالح (Mashhour and Saleh, 2010) حول تقييم التعلّم الإلكتروني في المؤسسات التعليمية الأردنية أشارت

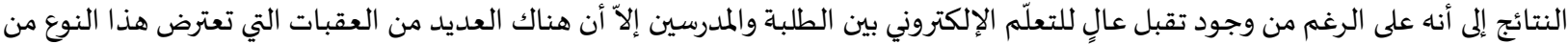

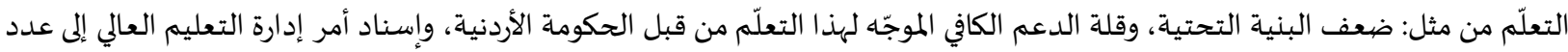
من الرعيل الأول من اصحاب النظرة التقليدية. وفي دراسة لأبي زبد (2011) حول العلاقة بين استخدام الإنترنت والمهارات الاجتماعية، هدفت إلى معرفة علاقة سوء استخدام الإنتانترنت بكلٍ من

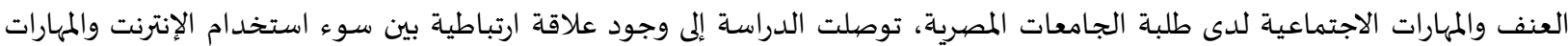

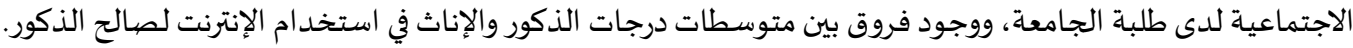

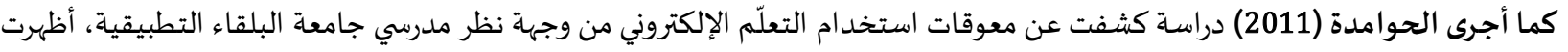

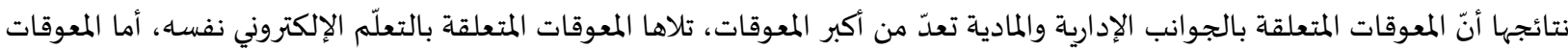

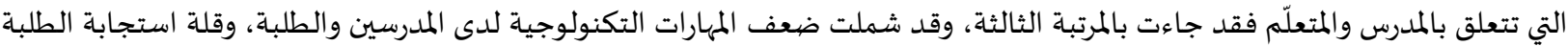

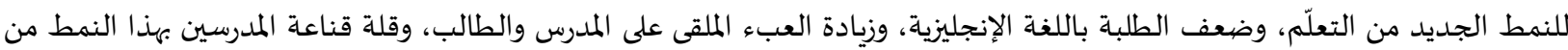
التعلّم.

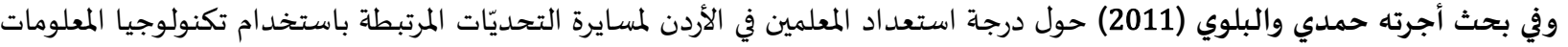

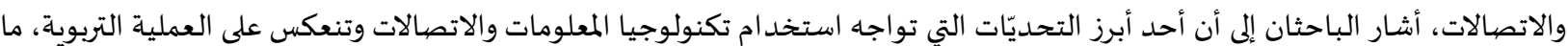

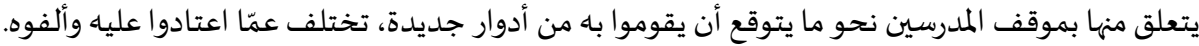
وفي دراسة أجراها قريشي والياس وروبينا ووبتي (Qureshi, Ilyas, Robina and Whitty, 2012) حول التحديّات التي تعترض الطلبة في تنفيذ

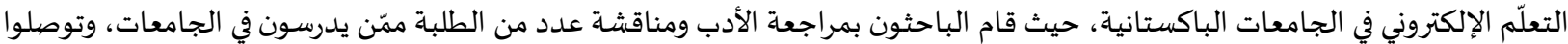

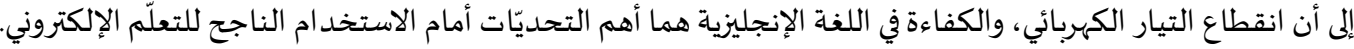

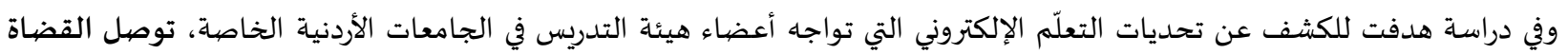

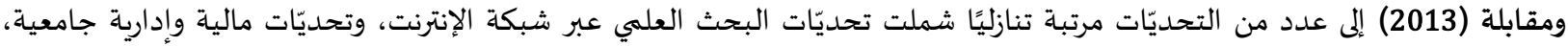

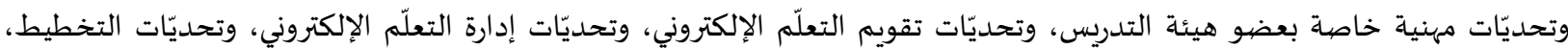
وتصيميم التعلّم الإلكتروني. وقد أشار فادي وفيو (Fadde and Vu, 2013) من خلال بحثهم عن التحديّات التي تواجه التعلّم المدمج إلى أن التحوّل إلى التعلّم الإلكتروني

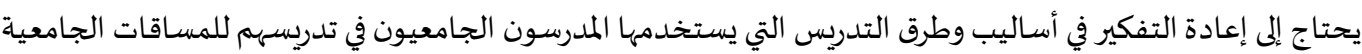


وفي دراسة أجراها المر ابحة (Almarabeh, 2014) على عينة من طلبة الجامعة الأردنية المسجلين في مواد مهارات الحاسوب، أظهرت نتائج

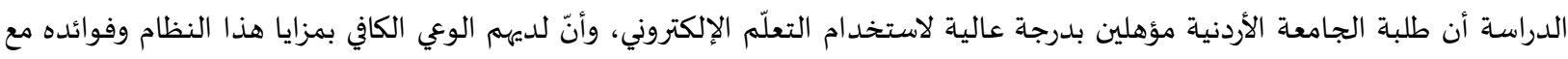
رغبتهم في تطوير استخدامه في المستقبل. فيما سعت دراسة المسلماني (2014) إلى تقديم رؤية مقترحة لدور التعليم في إعداد المواطن الرقهي للتغلب على النتائج السلبية المترتبة على

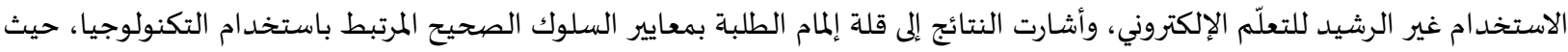
أن الطلبة بشكل عام غير مؤهلين للتعامل مع مجتمع التكنولوجيا بإيجابياته وسلبياته.

ولدى حديثهم عن الموضوعات والتحديّات التي تواجه التعلّم الإلكتروني أورد هيمنت وراجر ومانوهار (Hemant, Rajr and Manohar, 2014)

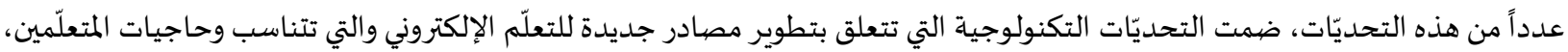
والتحديّات التي تتعلق بتطوير أشكال جديدة من وسائل التواصل والتفاعل، والتحديّات المتعلقة بتطوير معارف جديدة تبحث في التعلّم الفردي

والجمعي.

وفي مراجعة للأدبيات قام بها كل من إسلام وبي وسلاك (Islam, Bee and Slack, 2015) حول هذا الموضوع، أشار الباحثون إلى تركيز تلك الأدبيات على حاجات الطلبة، والنمو المتسارع للتكنولوجيا، وأثر العولمة وسرعة انتشار التكنولوجيا وتدفقها في العالم. وقد أورد الباحثون عدداً

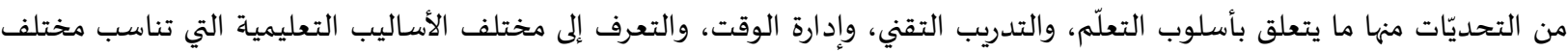

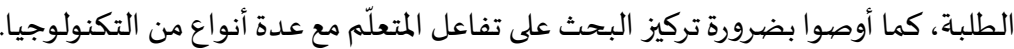
فيما بحث راسبوبفيك وسفيتانوفيك وجانكولفيك(Raspopvic and Cvetanovic and Jankulovic, 2016) في التحديّات المرتبطة بالتعلّم

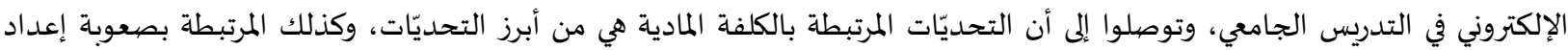
وتصيميم المواد التعليمياة، والمتعلقة بالاتصال والتواصل بين المدرسين والطلبة، وأبرزها غياب التواصل المباشر (Face to Face Interaction)،

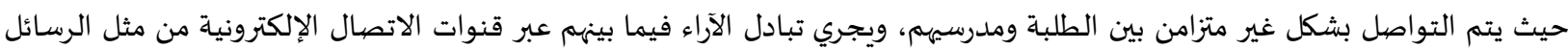

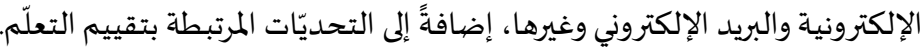
وفي المجال النفسي والاجتماعي أجرت العمار (2016) دراسة هدفت من خلالها إلى الكشف عن العلاقة بين التنمر الإلكتروني وإدمان الإنترنت

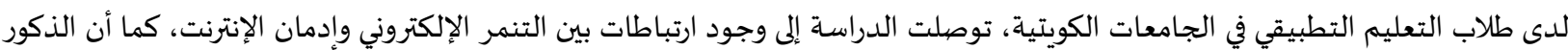
أكثر تنمرًا إلكترونيًا وإدمانا على الإنترنت من الإناث.

وفي دراسة بحثت في التحديّات التي تواجه تطبيق التعلّم الإلكتروني في مجال التربية، أشـار العتيبي (2014) إلى عدد من التحديّات التي تتعلق بالمتعلّم والمدرس والمجتمع والناحية المادية والفنية، أما بالنسبة للمتعلّمين فقد أورد الباحث صعوبة التحوّل من طرئ طريقة التعليم التقليدية إلى

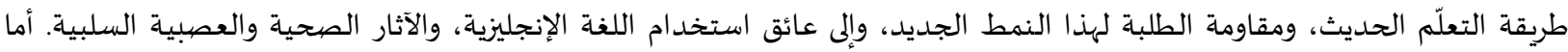

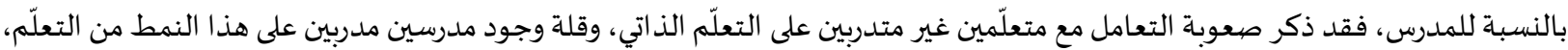

والاتجاه السلبي لدى بعض المدرسين نحوه.

فيما قام كيبرتشي وآنجي وسانتياجو (Kebritchi, Angie and Santiague, 2017) باستعراض الأدبيات التي بحثت في التعليم العالي عبر الإنترنت، وحددوا ثلاث فئات رئيسـة من التحديّات: تحديّات متعلقة بالمتعلّمين عبر الإنترنت مثل توقعاتهم واستعدادهم وهويتهم ومشـاركتهم،

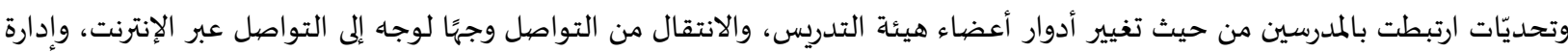

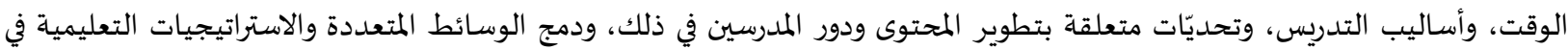

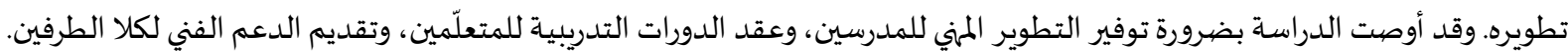

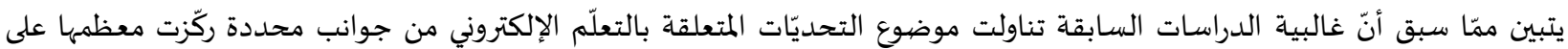

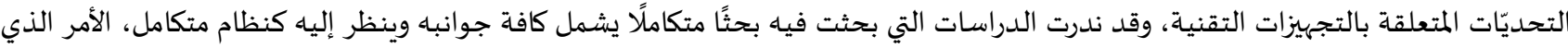

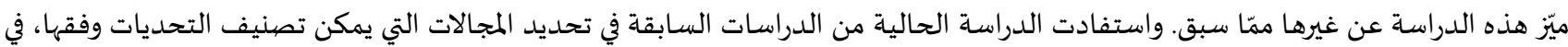

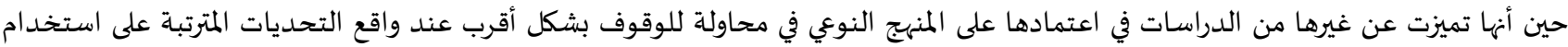

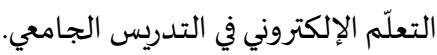

هذه دراسة تحليلية شاملة وناقدة اعتمدت مبدأ البحث المتعمّق في استقصاء التحديّات المستقبلية المترتبة على استخدام التعلّم الإلكتروني في

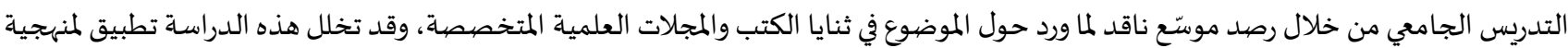
البحث النوعي في استفتاء الخبراء ومستخدمي ذلك النوع من التعلّم من مدرسين وطلبة جامعيين. 
وقد اعتمدت الدراسـة المنهج النوعي الذي يركّز على وصهف الظواهر والفهم المعمّقق لها، ويتناسب وطبيعـة الدراسـة الحالية، من خلال توظيف

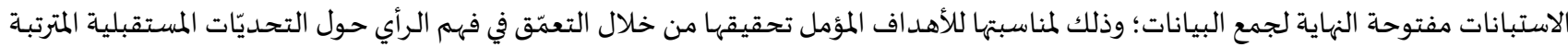
على استخدام التعلّم الإلكتروني في التدريس الجامعي؛ حيث وُزعّت الاستبانات المفتوحة على شـريحتين: شـريحة الخبراء (مدرسـون) في التعلّم الإلكتروني لمرحلة التدريس الجامعي، وشريحة الطلبة ممن يدرسون مسافات تعتمد على التعلّم الإلكتروني في الجامعة الأردنية.

1.3. عينة الدراسـة:

عينة الدراسة غرضيةة؛ بهدف انتقاء الحالات الغنية والمشبعة بالمعلومات. رؤوعي فهها التجانس بين أفرادها من حيث كونهم أصحاب خبرة طويلة في

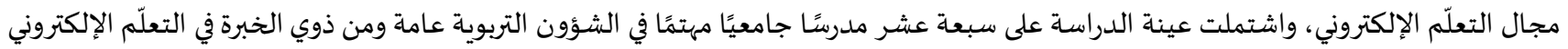

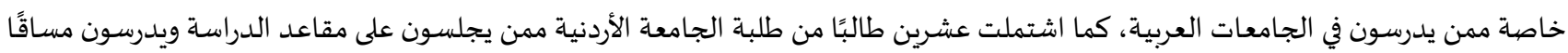
جامعيًا أو أكثر باستخدام التعلّم الإلكتروني.

2.3 أداتا الدراسةة: - 2.3

لتدعيم نتائج البحث والمساهمة في تحقيق أهدافه تم الاستعانة بأداتئ دراسة طُورتا بالاستئناس بالأدبيات السابقة والتشاور مع بعض المختصين

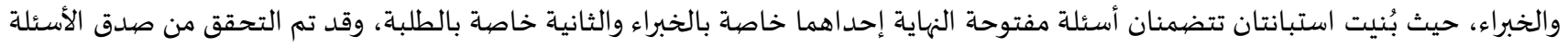

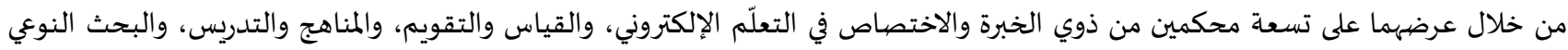
وإجراء التعديلات اللازمة. ثمّ طبقت الأسئلة على عينة استطلاعية ممن يعملون في مجال التعلّم الإلكتروني (أساتذة جامعيون، ومختصيون في إدارة مساقات التعلّم الإلكتروني)، للتحقق من وضوح الصياغة، وقدرة السؤال على تحقيق الهدف الذي وُضع من أجلهاء

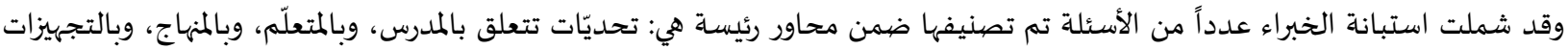

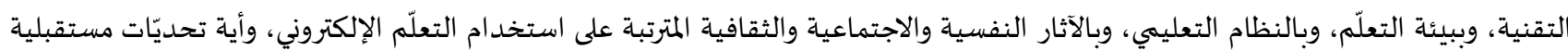
أخرى. أما استبانة الطلبة فقد شملت عددًا من الأسئلة تم تصنيفها ضيمن محاور رئيسة هي ما يلي: التحديّات التي تتعلق بالثقافة التكنولوجية، وبالدور

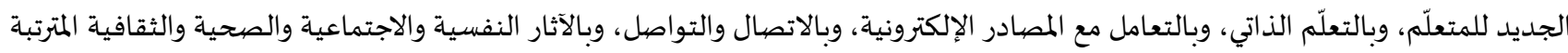

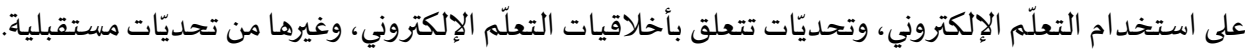
وقد تم تنفيذ أداتي الدراسـة من خلال إحدى الطرق الآتية: كتابة الأسئلة على ورقة مطبوعة، وقيام المستجيب بالإجابة ورقيًا على نفس الورقية. إرسال الأسئلة مطبوعة عبر البريد الإلكتروني، وإجابة المستجيب عليها طباعةً وإعادتها للباحث عبر البريد الالكتروني. إرسال الأسئلة مطبوعة عبر وسائل التواصل الاجتماعي (الوتساب، والفيسبوك)، وإجابة المستجيب عليها إما طباعةً أو شفويًّا وإعادتها للباحث عبر وسائل التواصل الاجتماعي. 3.3. مراحل تحليل أداتي الدراسـة: حاولت الباحثة رصيد كل صغيرة وكبيرة من الكلمات وردود الأفعال المختلفة من قبل المبحوثين. وعند تحليل الاستبانات وبياناتها حُوّلت المعلومات

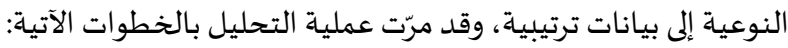

كتابة جميع البيانات التي تم الحصول عليها من الاستبانات الفردية (الكتابية والشفوية). جمع البيانات وتحليلها والتعرف إلهها من وسط كافة المعلومات أو الأحداث التفصيلية، واختيار أكثر البيانات نفعًا للدراسة الحالية. تنظيم البيانات وفق المجالات التي صيغت بها أسئلة الاستبانات. ترميز البيانات باستخدام رموز خاصية للكلمات المفتاحية (الترميز المفتوح) في إجابات أفراد عينة الدراسة (تم اشتقاق الكلمات المفتاحية من البيانات التي ترى الباحثة بأنها قد تزوّد الدراسة بإجابات عن أسئلتها). تصنيف المعلومات والبيانات وجمع كل منها في إطار أو نوع واحد (فرز البيانات). فهرسة البيانات، بتحديد أنواعها والإطار العام لها بطريقة مناسبة للدراسة ومنهجها، وتنظيمها ضمن فئات، وعنات وعلى شكل موضيوعات رئيسة وفرعية (الترميز المحوري). إيجاد التكرارات بحيث يتم ترميز الكلمة المتكررة وتصنف على أساس أهها وحدة معنى أي موضوع محدد يعبر عن مجموعة من المعلومات المتشابهة ذات العلاقة. مراجعة البيانات وقراءتها بشكل متعمّق، للتعرف على العلاقات والروابط بين مجموعات البيانات وإجراء مقارنات بينها للتعرف على أوجه التماثل والاختلاف، ودمجج المجموعات المتقاربة ببعضها وإعادة هيكلتها وتنظيمها. 
صياغة مجموعات البيانات وانتقاؤها على هيئة سلسلة من المجموعات التي تتناسب مع إجابة أسئلة الدراسة (الترميز الانتقائي). حساب التكرارات وتنظيم النتائج ضمن جداول.

التعبير عن النتائج على شكل رسوم بيانية لتسهيل قراءتها وتفسيرها. تفسير البيانات وتوضيح العلاقات والعناصر المرتبطة بمشكلة الدراسة.

4.3. المصيد اقية والموثوقية:

تتصف البحوث النوعية بأنها تقام في ظروف لا يمكن تكرارها بصورة دقيقة مجددًا في فترة أخرى وذلك لطبيعة البيانات المؤثرة في المبحوثين وبيئة البحث. وعليه يسعى الباحث النوعي إلى أن تتطابق نتائج دراسته مع الواقع لضمان الموثوقية، ولذا فقد اتخذت الدراسة الحالية الخطوات الآتية

لضمان مصداقاقية النتائج وجودنها:

تصميم منهج الدراسة بصورة دقيقة وفق إجراءات ضمان موثوقية البحوث النوعية.

تحليل محتوى إجابات الاستبانات الفردية بعد أسبوعين من التحليل الأول لضمان ثبات التحليل.

تحليل النتائج من قبل باحث آخر، وإعطاءه المجال للتعليق بما يراه مناسبًا للتحقق من واقعية النتائج.

5.3. إجراءات الدراسـة:

تـم اجـراء الدراسـة من خلال تطبيق تقنية الأسئلة مفتوحة النهايـة (Open-ended questioner) في تصميم استبانتين إحداهما خاصة

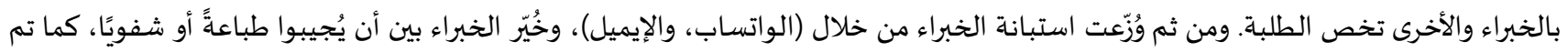
توزيع الاستبانة المفتوحة على الطلبة وجمعها بعد تعبئتها. وقد استغرقت عملية التوزيع والجمع أربعة أسابيع تقريبًا. وقد سارت العملية على النحو

توزيع الاستبانات مفتوحة النهاية على خبراء في التعلّم الإلكتروني لمرحلة التدريس الجامعي، وهم مجموعة من المدرسين الجامعيين في عدد من

الجامعات العربية.

توزيع الاستبانات مفتوحة النهاية على طلبة الدراسات العليا ومرحلة البكالوريوس في الجامعة الأردنية ممن يدرسون مساقات تعتمد على التعلّم الإلكتروني. تفريخ الإجابات التي جُمعت من الخبراء والطلبة، وتدوينها، وتصنيفها، وتحليلها، وترميزها، وتبويها، ومن ثم تجميعها في فئات.

4. ن نتائج الدراسـة ومناقشتها: للإجابة عن أسئلة الدراسة جُمعت الإجابات الخاصهة بالخبراء والطلبة، وبعد تصنيفها وتدوينها وتحليلها وترميزها وتبويها وتجميعها في فئات،

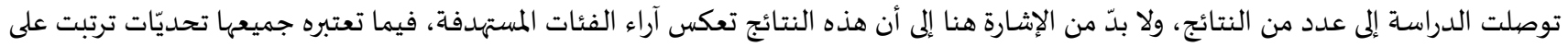

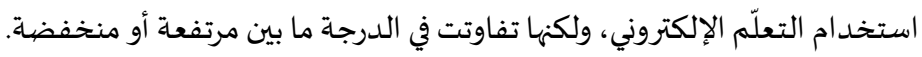

1.4. نتائج السؤال الأول:

جاءت إجابات الخبراء على السؤال الخاص بالتحؤ التحديّات المستقبلية المترتبة على استخدام التعلّم الإلكتروني في التدريس الجامعي المتعلقة بكل من: المدرس، والمتعلّم، والمنهاج، والبيئة التعلّمية والتجهيزات التهات التقنية، والنظام التعليمي وفق الآتي:

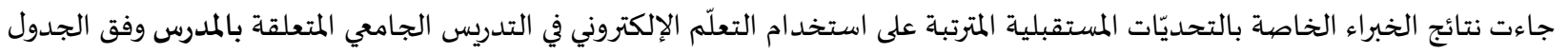

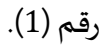

\begin{tabular}{|c|c|c|}
\hline 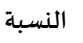 & التكرارات & التحديّات المتعلقة بالمدرس \\
\hline \multicolumn{3}{|l|}{ 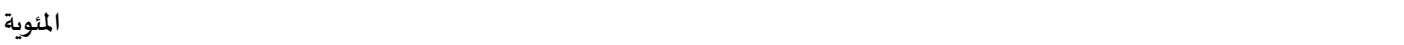 } \\
\hline $65 \%$ & 11 & ضعف الوعي بالثقافة التكنولوجية، وقلة الإقبال على التدربب \\
\hline $42 \%$ & 7 & مقاومة التجديد أو التغيير بسبب الاعتياد على النمط التقليدي \\
\hline $42 \%$ & 7 & الحاجة إلى وقت وجهد إضافي في الإعداد والتصميم \\
\hline $42 \%$ & 7 & قلة الوعي بتغيَّر دور المدرس، والضيعف في توظيف الاستراتيجيات \\
\hline $29 \%$ & 5 & ضعف قدرة بعض المدرسين على مواكبة التطورات والتغيرات المتسارعة \\
\hline $24 \%$ & 4 & قلة الخبرة في المهارات التكنولوجية وتفوق بعض الطلبة على مدرسههم فهيا \\
\hline $24 \%$ & 4 & مشكلات في الاتصال والتواصل \\
\hline
\end{tabular}


يتبين من جدول (1) أن أبرز التحديّات المستقبلية للتعلّم الإلكتروني في التدريس الجامعي والمتعلقة بالمدرس، جاء التحدي الخاص بضعف الوعي بالثقافة التكنولوجياة، وما يترتب عليه من ضعف الإقبال على التدريب في المرتبة الأولى، بينما جاء في مرتبة دنيا الضعف التهد العام وقلة الخبرة في المهارات التكنولوجية والتعامل مع الأجهزة والبرمجيات، وتفوق الطلبة على مدرسيهم في بعض المهارات الحاسوبية، إضافةً إلى مشكلات في الاتصال والتواصل.

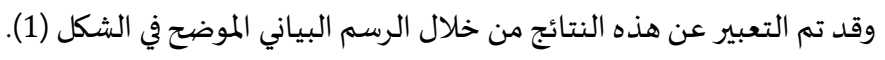

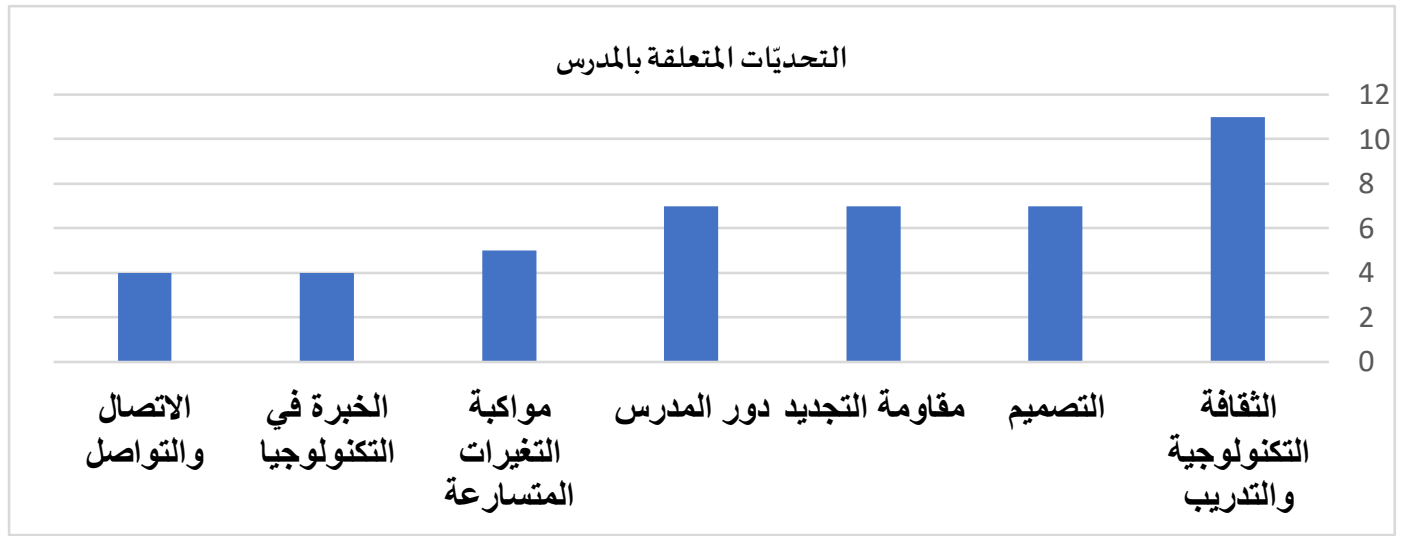

شكل (1): التحديّات المستقبلية للتعلّم الإلكتروني من وجهة نظر الخبراء المتعلقة بالمدرس

فيما جاءت نتائج الخبراء الخاصة بالتحديّات المستقبلية المترتبة على استخدام التعلّم الإلكتروني في التدريس الجامعي المتعلقة بالمتعلّم وفق

الجدول رقم (2).

\begin{tabular}{|c|c|c|}
\hline المئوبة & 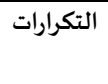 & التحديّات المتعلقة بالمتعلّم \\
\hline $76 \%$ & 13 & ضعف في الثقافة التكنولوجية، وقلة الوعي بتغيّر دور المتعلّم \\
\hline $53 \%$ & 9 & مشكلات في التعلَم الذاتي \\
\hline $35 \%$ & 6 & الكلفة المادية \\
\hline $29 \%$ & 5 & ضعف في مهارات الاتصال والتواصل \\
\hline $18 \%$ & 3 & قلة مواكبة المستجدات، والاعتياد على التعلّم التقليدي \\
\hline $6 \%$ & 1 & قلة توفر المصادر باللغة الأم \\
\hline
\end{tabular}

يتبين من جدول (2) أن أبرز التحديّات المستقبلية للتعلّم الإلكتروني في التدريس الجامعي والمتعلقة بالمتعلّم، جاء في مرتبة مرتفعة التحدي

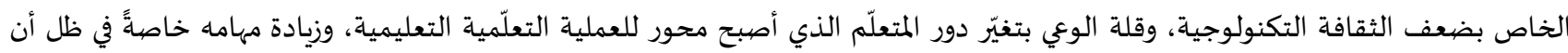

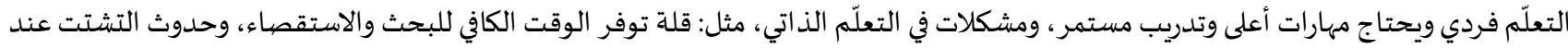

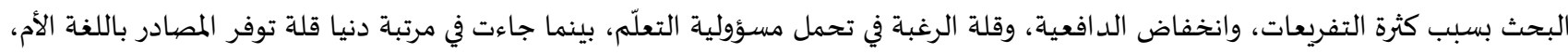

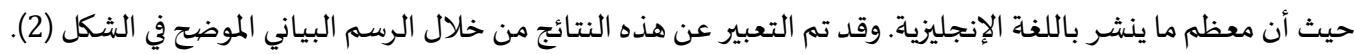

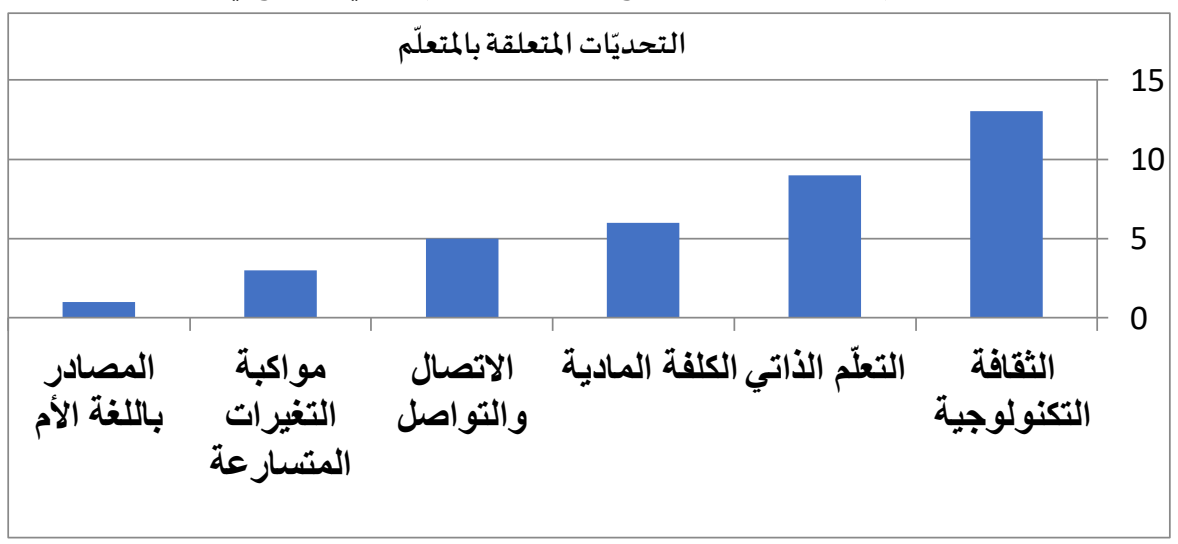

شكل (2): التحديّات المستقبلية للتعلّم الإلكتروني من وجهة نظر الخبراء المتعلقة بالمتعلّم 
جاءت نتائج تحليل إجابات الخبراء الخاصة بالتحديّات المستقبلية المترتبة على استخدام التعلّم الإلكتروني في التدريس الجامعي المتعلقة بالمنهاج

وفق الجدول رقم (3).

جدول (3): نتائج استبانات الخبراء حول التحديّات المتعلقة بالمنهاج

\begin{tabular}{|c|c|c|}
\hline المئوبة & 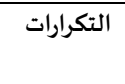 & التحديّات المتعلقة بالمنهاج \\
\hline $42 \%$ & 7 & الكلفة المادية \\
\hline $42 \%$ & 7 & صعوبة تصميم المناهج \\
\hline $29 \%$ & 5 & زخم المناهج وضخامتها، ووجود البرمجيات بلغات أجنبية \\
\hline $24 \%$ & 4 & صعوبة في تقييم مناهج التعلّم الإلكتروني، والتقييم في مناهج التعلّم الإلكتروني \\
\hline $24 \%$ & 4 & 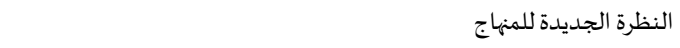 \\
\hline $18 \%$ & 3 & ضعف مواكبة المنهاج للتغيرات المتسارعة \\
\hline $18 \%$ & 3 & صعوبة مواءمة المناهج للتعلّم الذاتي والتعلّم الفردي \\
\hline $12 \%$ & 2 & الحاجة إلى وقت إضافي للتصميم والإعداد \\
\hline
\end{tabular}

يتبين من جدول (3) أن أبرز التحديّات المستقبلية للتعلّم الإلكتروني في التدريس الجامعي والمتعلقة بالمنهاج، جاء التحدي الخاص بالكلفة المادية، وصعوبة تصهيم المناهج، وما يرتبط بالتصميم من الحاجة إلى خبراء في التصيميم وطرق التدريس في المرتبة الأولى، بينما جاءت في مرتبة دنيا ضعف

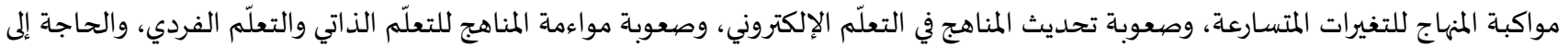

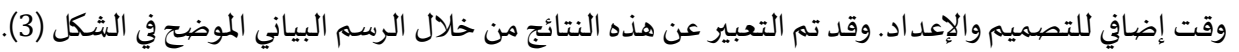

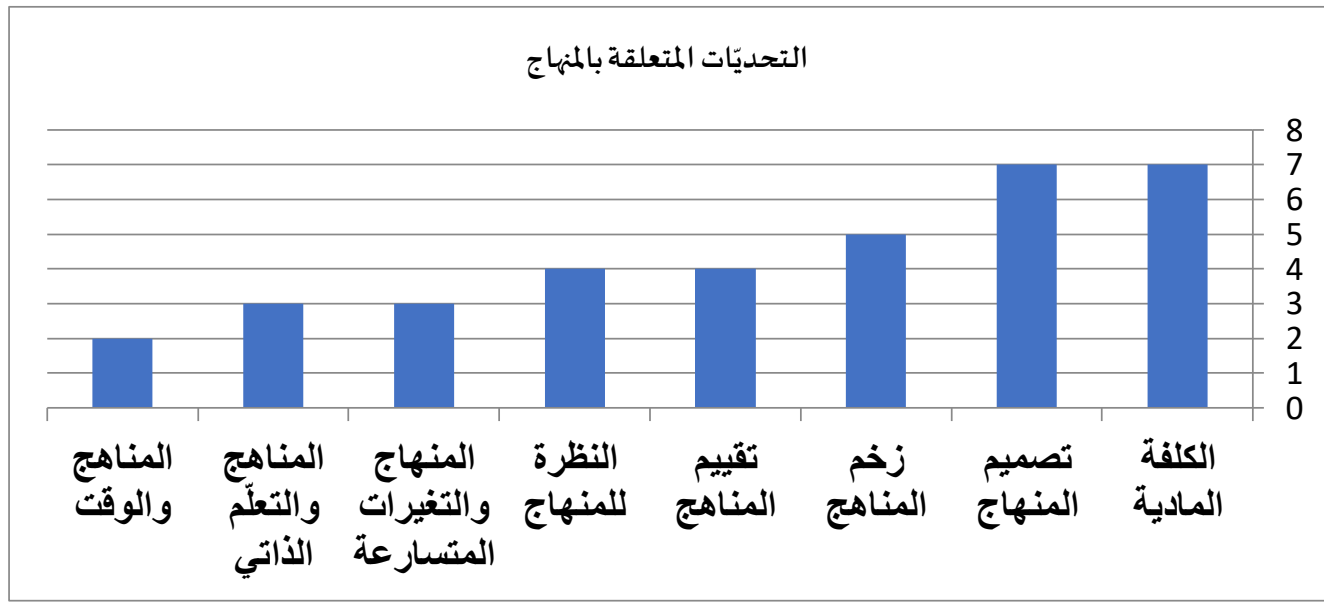

شكل (3): التحديّات المستقبلية للتعلّم الإلكتروني من وجهة نظر الخبراء المتعلقة بالمههاج

جاءت نتائج تحليل إجابات الخبراء الخاصة بالتحديّات المستقبلية المترتبة على استخدام التعلّم الإلكتروني في التدريس الجامعي المتعلقة بالبيئة التعلّمية والتجهيزات التقنية وفق الجدول رقم (4).

جدول (4): نتائج استبانات الخبراء حول التحديّات المتعلقة بالبيئة التعلّمية والتجهيزات التقنية

\begin{tabular}{|c|c|c|}
\hline المئوية & 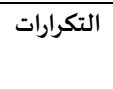 & التحديّات المتعلقة بالبيئة التعلّمية والتجهيزات التقنية \\
\hline $76 \%$ & 13 & البيئة المادية والتجهيزات \\
\hline $65 \%$ & 11 & 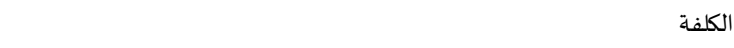 \\
\hline $53 \%$ & 9 & 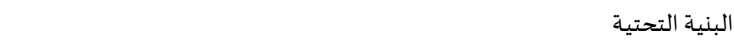 \\
\hline $53 \%$ & 9 & التحديث المستمر للبرامج والأجهزة \\
\hline $47 \%$ & 8 & 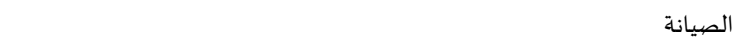 \\
\hline $29 \%$ & 5 & المختصهون بالتعامل مع التجهيزات \\
\hline $29 \%$ & 5 & بطء الشبكة وانقطاعها ومشكلات التحميل \\
\hline $12 \%$ & 2 & البيئة الافتراضية البية \\
\hline $6 \%$ & 1 & قلة توافر البرامج باللغة الأم \\
\hline
\end{tabular}




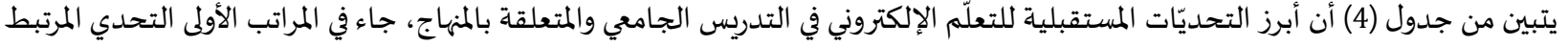

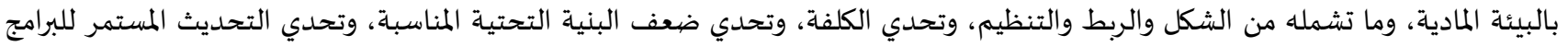
والأجهزة. بينما جاءت في مرتبة دنيا البيئة الافتراضية، وقلة توافر البرامج باللغة الأم. وقد تم التعبير عن هذه النتائج من خلال الرسم البياني الموضح في

الشكل (4).

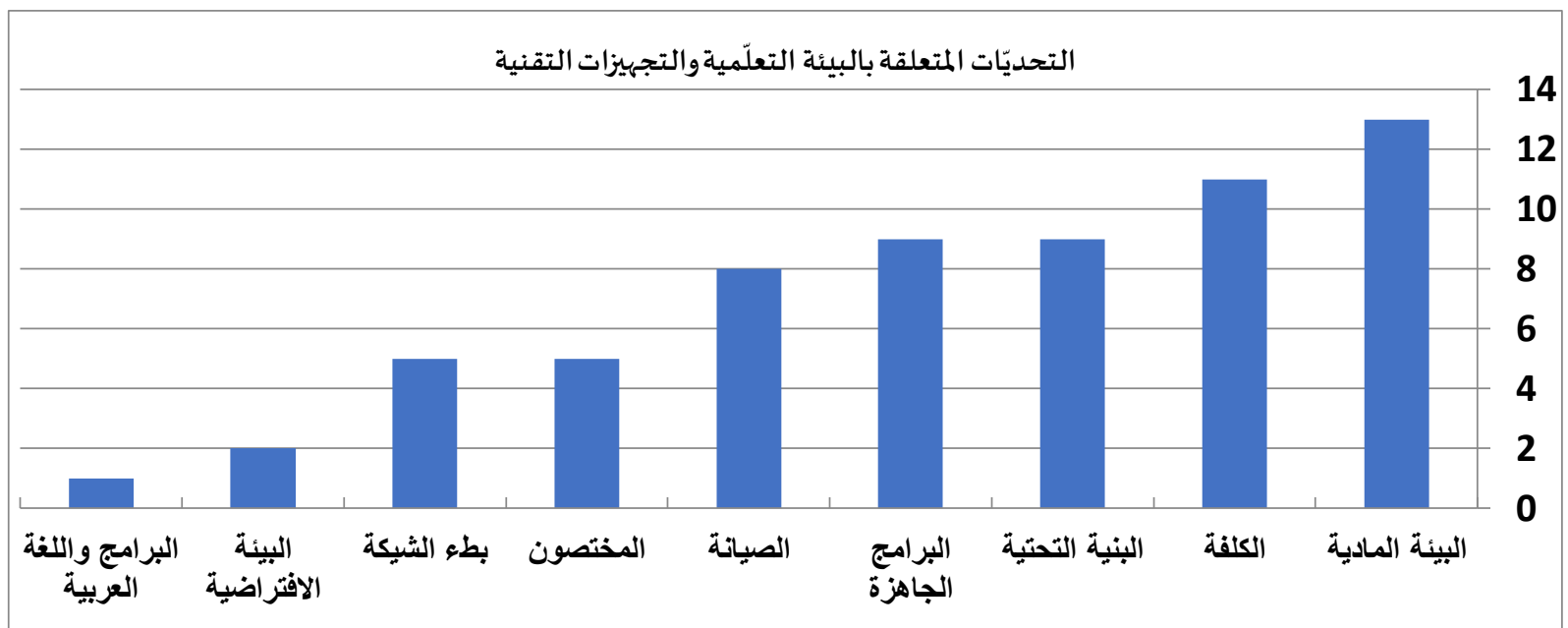

شكل (4): التحديّات المستقبلية للتعلّم الإلكتروني من وجهة نظر الخبراء المتعلقة بالبيئة التعلّمية والتجهيزات التقنية

جاءت نتائج تحليل إجابات الخبراء الخاصة بالتحديّات المستقبلية المترتبة على استخدام التعلّم الإلكتروني في التدريس الجامعي المتعلقة بالنظام

التعليمي وفق الجدول رقم (5).

\begin{tabular}{|c|c|c|}
\hline 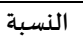 & 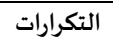 & التحديّات المتعلقة بالنظام التعلييم \\
\hline \multicolumn{3}{|l|}{ 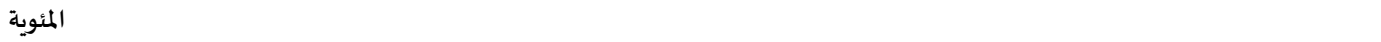 } \\
\hline $35 \%$ & 6 & قلة وجود سياسات واضحة، وقلة الوعي بالمفهوم \\
\hline $24 \%$ & 4 & التحول من نظام تقليدي إلى نظام تكنولوجي جديد \\
\hline $12 \%$ & 2 & مقاومة التغيير وتقبل المجتمع \\
\hline $12 \%$ & 2 & التدريب على كيفية تطبيق النظام \\
\hline $6 \%$ & 1 & المعيقات الإدارية وقلة وعي متخذي القرار \\
\hline $6 \%$ & 1 & النظام المستخدم في التقييم والدرجات \\
\hline $6 \%$ & 1 & التكامل والتخطيط \\
\hline
\end{tabular}

يتبين من جدول (5) أن أبرز التحديّات المستقبلية للتعلّم الإلكتروني في التدريس الجامعي والمتعلقة بالنظام التعليهي، جاءت في المراتب الأولى

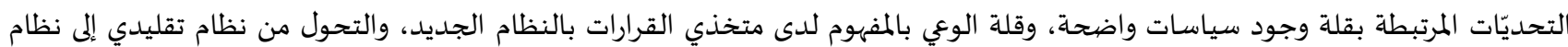

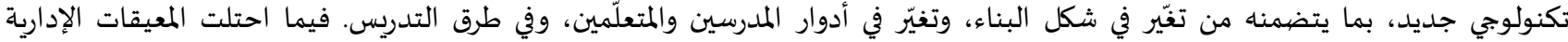

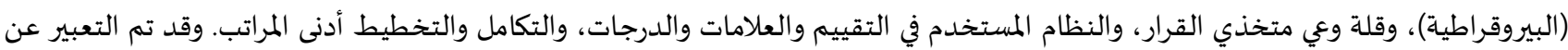
هذه النتائج من خلال الرسم البياني الموضح في الشكل (5). 


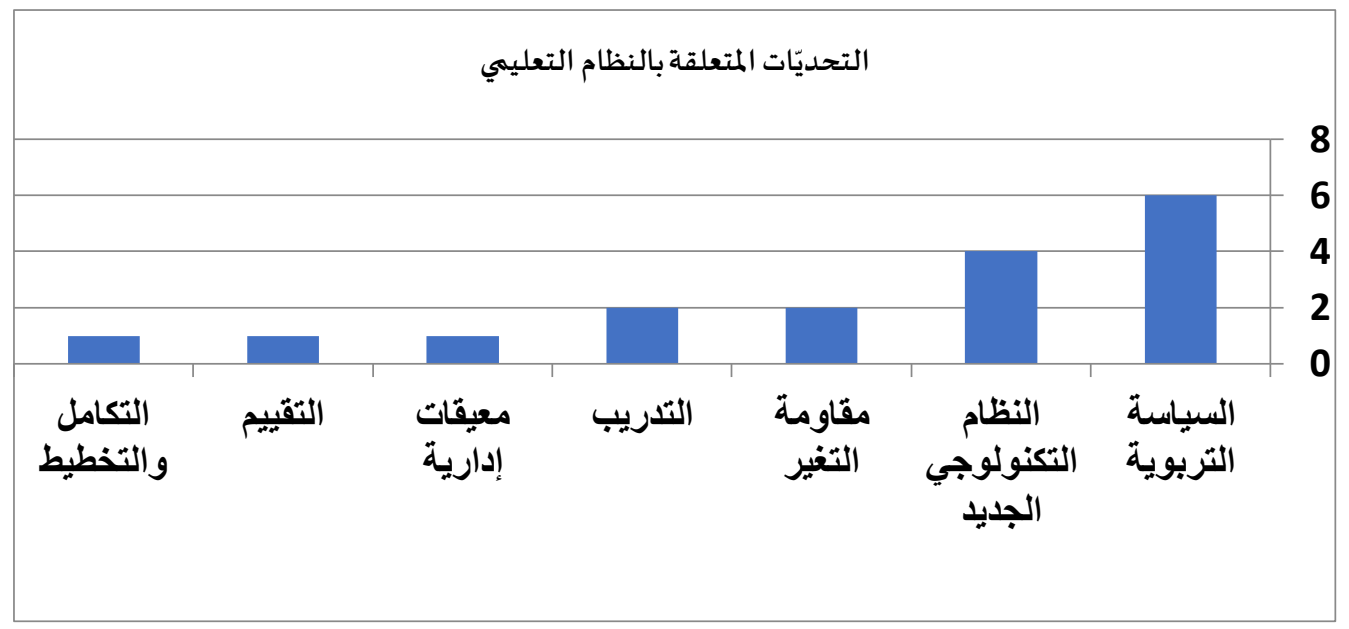

شكل (5): التحديّات المستقبلية للتعلّم الإلكتروني من وجهة نظر الخبراء المتعلقة بالنظام التعليهي

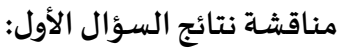

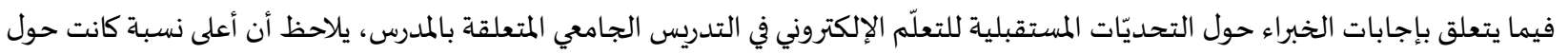

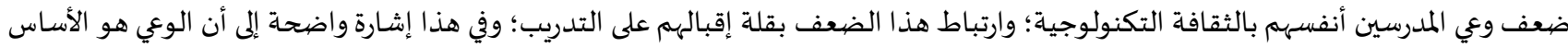

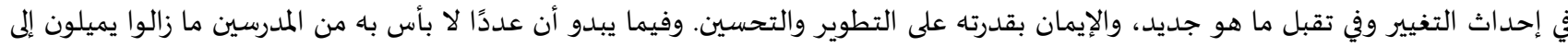

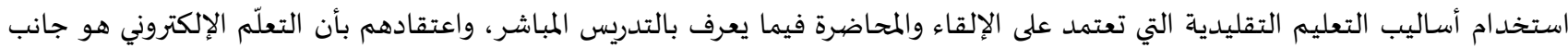

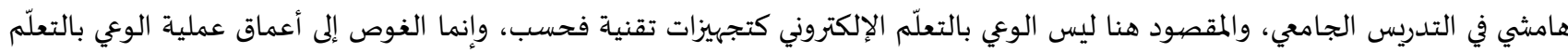

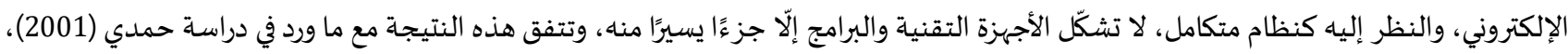
ودراسة حمدي والبلوي (2011)، ودراسة كيبرتشي وآخرون. (Kebritchi, et al., 2017)

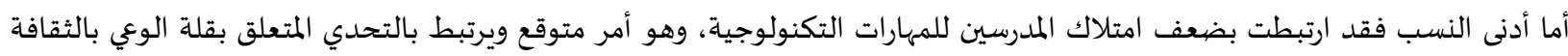

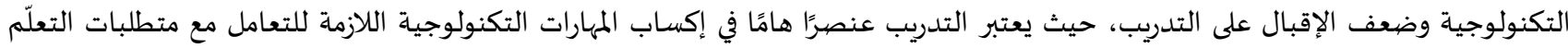

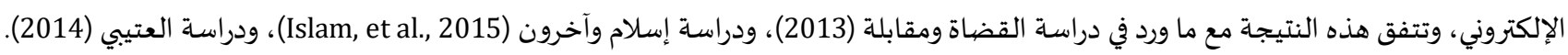

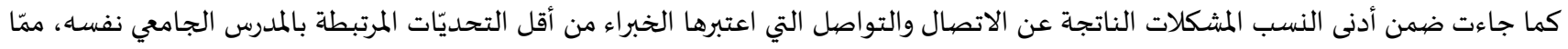

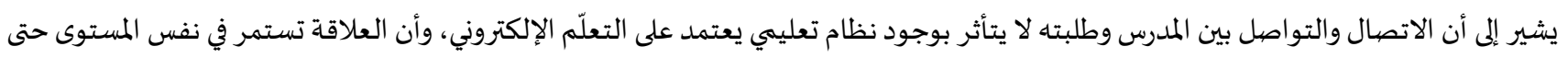

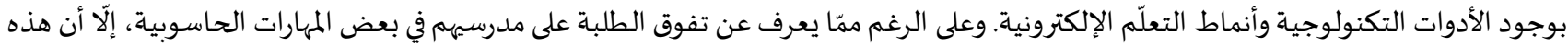

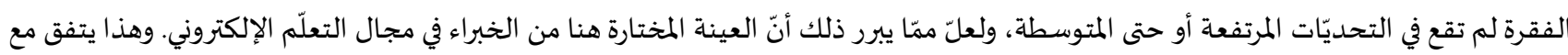
ما جاء في دراسة هيمنت وآخرون. (Hemant, et al., 2014)

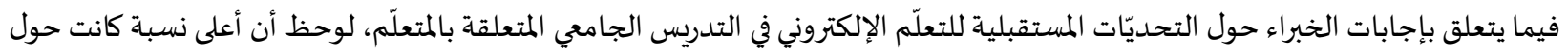

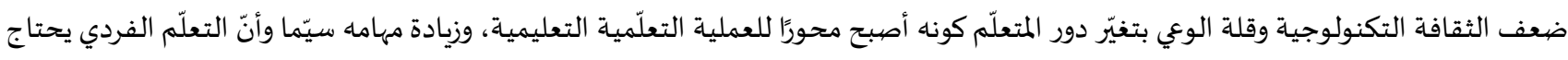

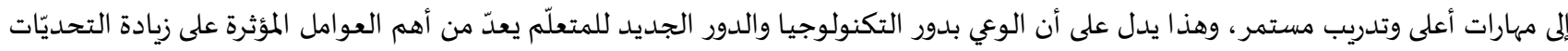

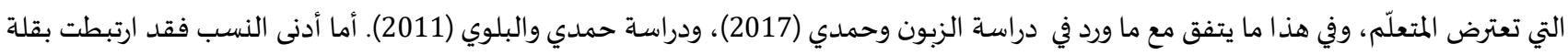

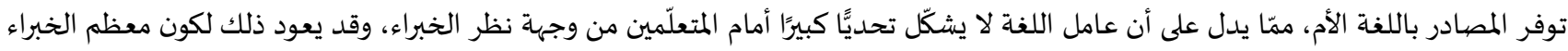

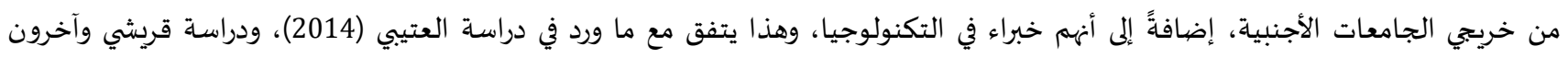

(Qureshi, et al., 2012)

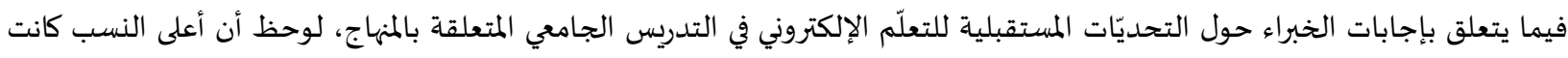

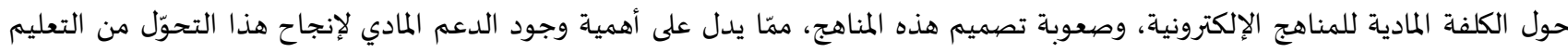

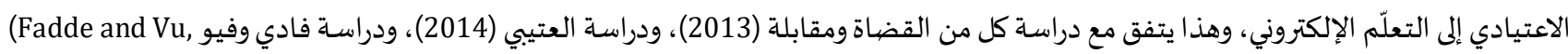

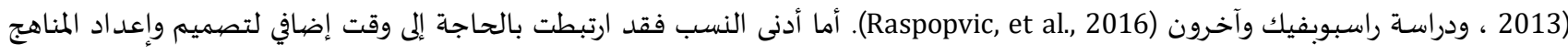

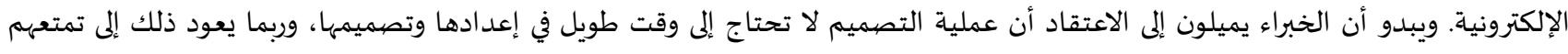

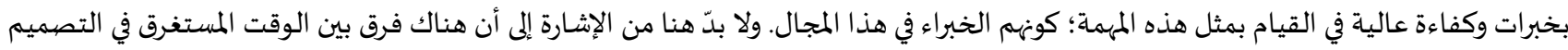


والإعداد، والوقت المستغرق في الاستخدام، فإذا كانت القضية تتعلق في الوقت اللازم للتصميم والإعداد، فمن المتوقع أن يكون الوقت هو أحد أبرز

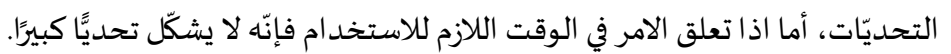

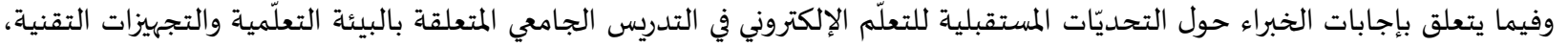

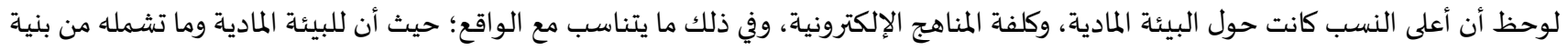
تحتية تتناسب والتجهيزات التقنية أهمية كبيرة في توظيف التكنولوجيا بشكل فمّال في التدريس الجامعي، وهذا يتفق مع ما ورد في دراسة مشهيور

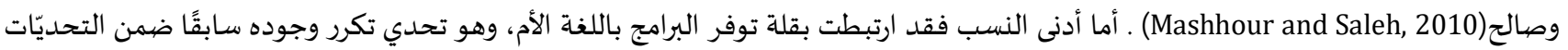

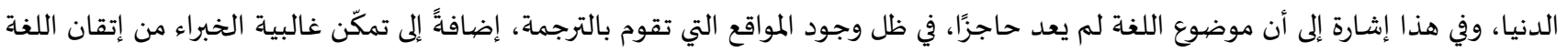
الإنجليزية إلى جانب اللغة العربية الأم.

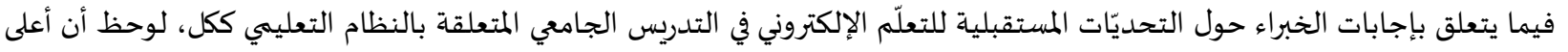

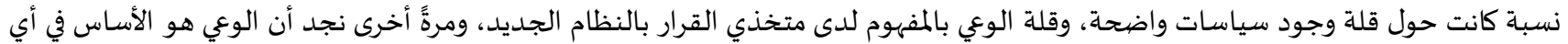

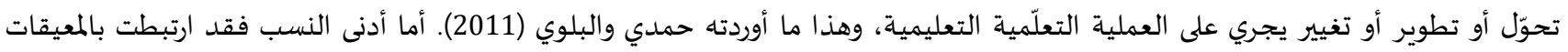

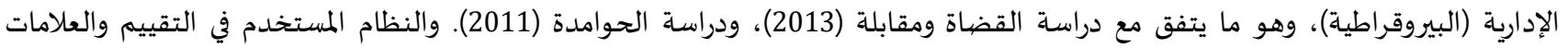

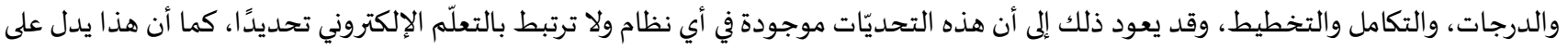

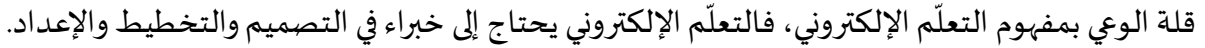

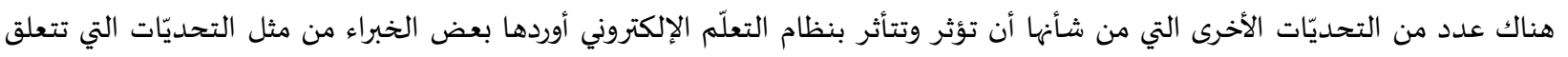

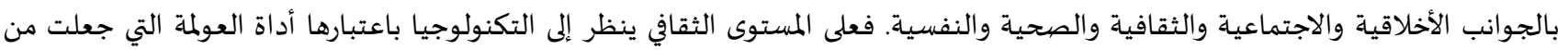

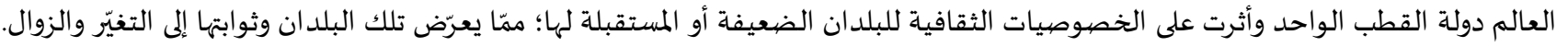

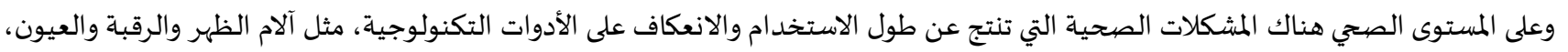

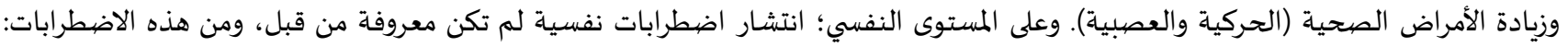

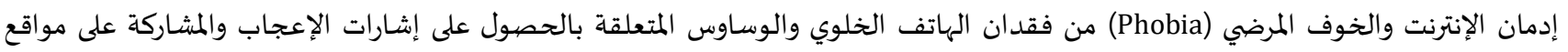
التواصل الاجتماعي، وغير ذلك الكثير.

$$
\text { 2.4 نتائج السؤال الثاني: }
$$

جاءت إجابات الطلبة على السؤال الخاص بالتحديّات المستقبلية المترتبة على استخدام التعلّم الإلكتروني في التدريس الجامعي المتعلقة بكل من:

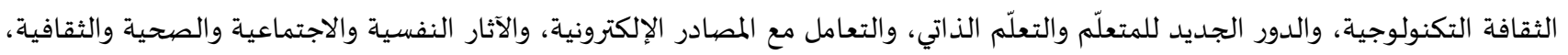
والاتصال والتواصل، وأخلاقيات التعلّم الإلكتروني على النحو الآتي:

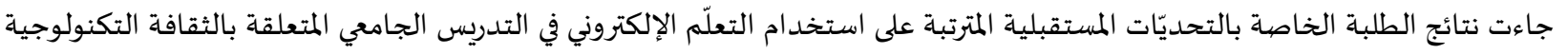

وفق الجدول رقم (6). - اكت

جدول (6): نتائج استبانات الطلبة حول التحديّات التي تتعلق بالثقافة التكنولوجية

\begin{tabular}{|c|c|c|}
\hline النسبة المئوية & 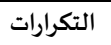 & التحديّات المتعلقة بالثقافة التكنولوجية \\
\hline $55 \%$ & 11 & مقاومة التجديد والميل للاعتماد على نمط معين \\
\hline $40 \%$ & 8 & مفهوم التعلّم الإلكتروني \\
\hline $35 \%$ & 7 & النظرة للمقرر الجامعي مقابل الإلكتروني \\
\hline $20 \%$ & 4 & الشعور بأن المتعلَّم اكفأ من المدرس \\
\hline $5 \%$ & 1 & القناعة الذاتية بالتعلّم الإلكتروني \\
\hline
\end{tabular}

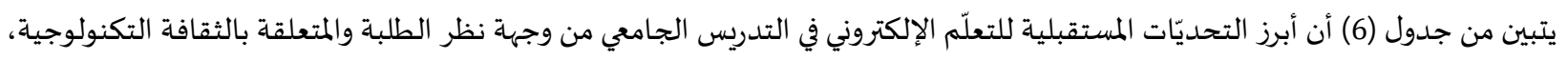

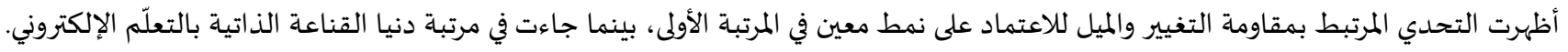

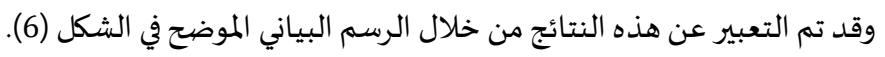




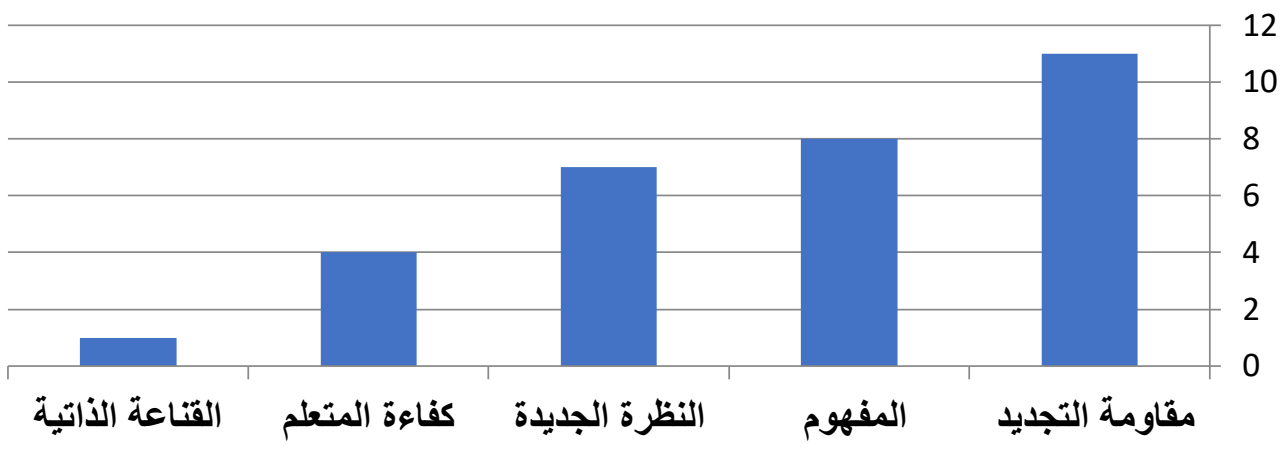

شكل (6): التحديّات المستقبلية للتعلّم الإلكتروني من وجهة نظر الطلبة المتعلقة بالثقافة التكنولوجية

جاءت نتائج تحليل إجابات الطلبة الخاصية بالتحديّات المستقبلية المترتبة على استخدام التعلّم الإلكتروني في التدريس الجامعي المتعلقة بالدور الجديد للمتعلِّم والتعلّم الذاتي وفق الجدول رقم (7).

\begin{tabular}{|c|c|c|}
\hline 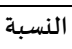 & 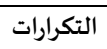 & التحديَّات المتعلقة بالدور الجديد للمتعلّم والتعلّم الذاتي \\
\hline \multicolumn{3}{|l|}{ 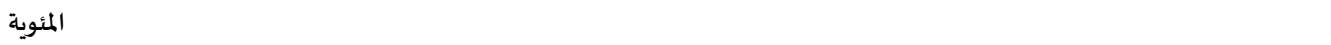 } \\
\hline $40 \%$ & 8 & التكيّف مع متطلبات التعلّم الإلكتروني الجديدة \\
\hline $40 \%$ & 8 & زيادة الأعباء والمسؤوليات الملقاة على عاتق المتعلّم \\
\hline $30 \%$ & 6 & تغير طرق وأدوات التقويم \\
\hline $25 \%$ & 5 & صعوبة التعامل مع الامتحانات الإلكترونية \\
\hline $15 \%$ & 3 & المتعلّم كمخطط لتعلّمه \\
\hline $15 \%$ & 3 & فردية التعلّم \\
\hline $10 \%$ & 2 & مقارنة أداء المتعلّم بذاته لا بأقرانه \\
\hline $5 \%$ & 1 & المتعلّم كناقد \\
\hline $5 \%$ & 1 & 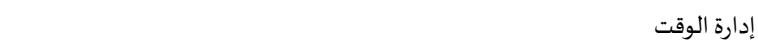 \\
\hline
\end{tabular}

يتبين من جدول (7) أن أبرز التحديّات المستقبلية للتعلّم الإلكتروني في التدريس الجامعي من وجهة نظر الطلبة والمتعلقة بالدور الجديد للمتعلّم

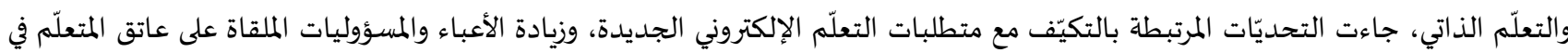
المراتب الأولى، بينما جاءت في مرتبة دنيا تغير دور المتعلّم إلى مخطط لتعلّمه وناقد، وفردية التعلّم، ومقارنة أداء المتعلّم بذاته لا بأقرانه، وإدارة الوقت.

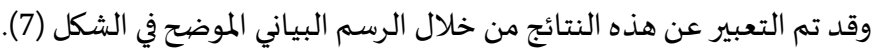

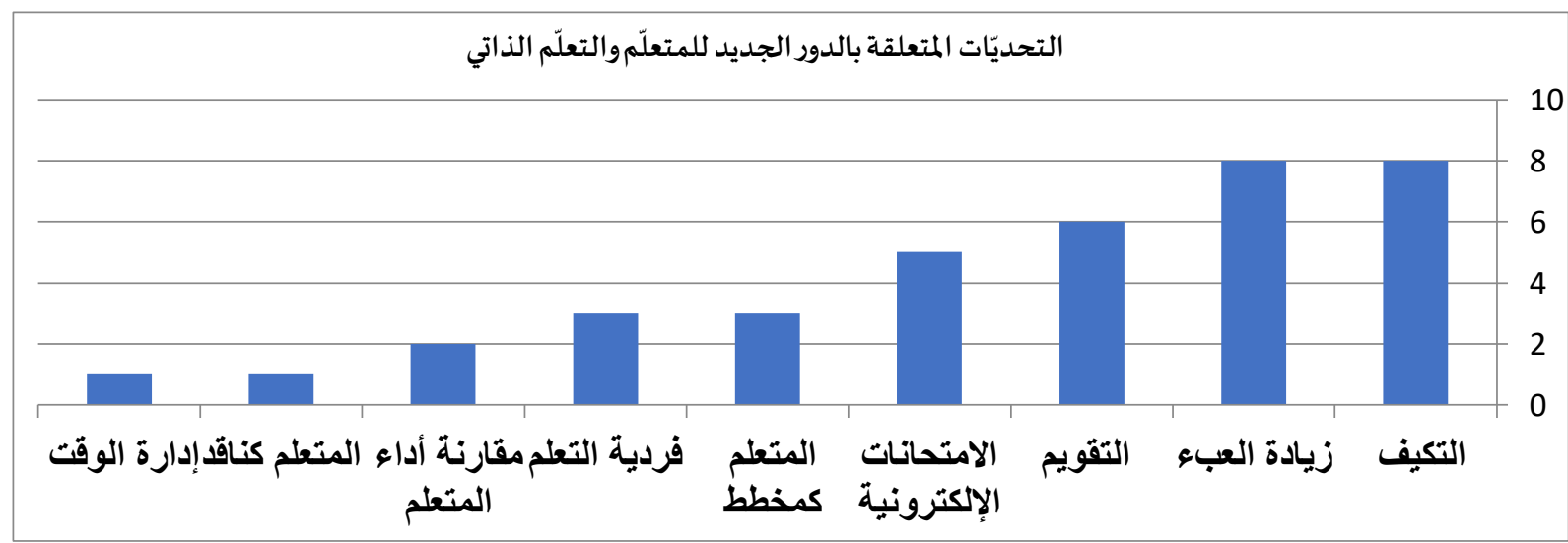

شكل (7): التحديّات المستقبلية للتعلّم الإلكتروني من وجهة نظر الطلبة المتعلقة بالدور الجديد للمتعلّم والتعلّم الذاتي

جاءت نتائج تحليل إجابات الطلبة الخاصة بالتحديّات المستقبلية المترتبة على استخدام التعلّم الإلكتروني في التدريس الجامعي المتعلقة بالتعامل مع المصيادر الإلكترونية وفق الجدول رقم (8). 
جدول (8): نتائج استبانات الطلبة حول التحديّات التي تتعلق بالتعامل مع المصبادر الإلكترونية

\begin{tabular}{|c|c|c|}
\hline النسبة المئوية & 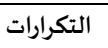 & التحديّّات المتعلقة بالتعامل مع المصادر الإلكترونية \\
\hline $55 \%$ & 11 & ضعف المهارات في التعامل مع التجهيزات \\
\hline $55 \%$ & 11 & التشتت بسبب كثرة التفريعات \\
\hline $30 \%$ & 6 & انقطاع الشبكة المفاجئ \\
\hline $30 \%$ & 6 & 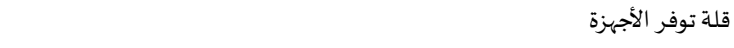 \\
\hline $30 \%$ & 6 & قلة توفر البرامج التعليمية المناسبة والناطقة باللغة العربية \\
\hline $30 \%$ & 6 & التغير المتسارع للبرمجيات والتجهيزات \\
\hline $25 \%$ & 5 & ارتفاع الكلفة المادية للأجهزة والبرمجيات \\
\hline $20 \%$ & 4 & 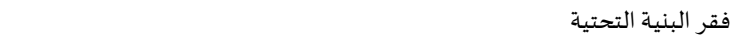 \\
\hline $15 \%$ & 3 & كثرة المشكلات الفنية \\
\hline $15 \%$ & 3 & ضعف الابتكار والابداع في تصميم البرمجيات بسبب الاعتماد على التطبيقات الجاهزة \\
\hline $10 \%$ & 2 & تغير طبيعة المصادر من مواد مقررة إلى مصادر مفتوحة \\
\hline $5 \%$ & 1 & صبعوبة الوصول إلى المعلومات \\
\hline
\end{tabular}

يتبين من جدول (8) أن أبرز التحديّات المستقبلية للتعلّم الإلكتروني في التدريس الجامعي من وجهة نظر الطلبة والمتعلقة بالتعامل مع المصيادر، جاءت التحديّات المرتبطة بضعف المهارات في التعامل مع التجهيزات، والتشتت بسبب كثرة التفريعات، والتغيّر المتسارع للبرمجيات والتجهيزات في المرتبة فئة الأولى، بينما جاءت في مرتبة دنيا كثرة المشكلات الفنية، وضعف الابتكار والإبداع في تصهميم البرمجيات بسبب الاعتمات بلتهاد على التطبيقات الجاهزة، وتغيّر طبيعة المصادر من مواد مقررة إلى مصادر مفتوحة، وصعوبة الوصول للمعلومات. وقد تم التعبير عن هذه النتائج من خلال الرسم البياني الموضح في

(8) الشكل

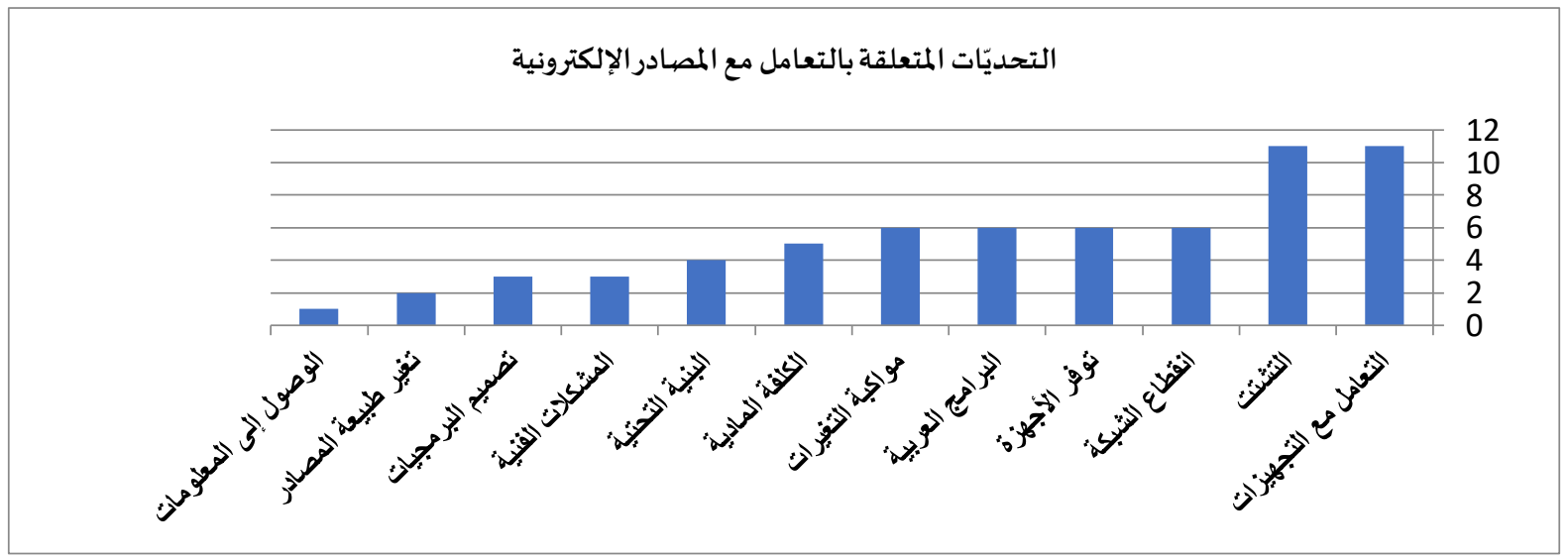

شكل (8): التحديّات المستقبلية للتعلّم الإلكتروني من وجهة نظر الطلبة المتعلقة بالتعامل مع المصادر الإلكترونية

جاءت نتائج تحليل إجابات الطلبة الخاصة بالتحديّات المستقبلية المترتبة على استخدام التعلّم الإلكتروني في التدريس الجامعي المتعلقة بالآثار

النفسية والاجتماعية والصحية والثقافية وفق الجدول رقم (9).

جدول (9): نتائج استبانات الطلبة حول التحديّات التي تتعلق بالآثار النفسية والاجتماعية والصحية والثقافية

\begin{tabular}{|c|c|c|}
\hline 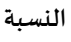 & 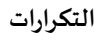 & التحديّات المتعلقة بالآثار النفسية والاجتماعية والصحية والثقافية \\
\hline \multicolumn{3}{|l|}{ 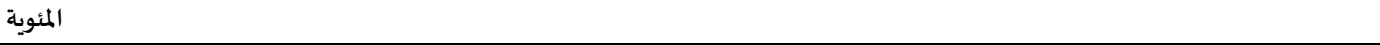 } \\
\hline $50 \%$ & 10 & الأمراض الصحية \\
\hline $45 \%$ & 9 & 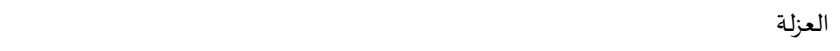 \\
\hline $40 \%$ & 8 & الإدمان \\
\hline $35 \%$ & 7 & 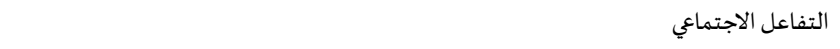 \\
\hline $25 \%$ & 5 & الدخول إلى مواقع غير مقبولة اجتماعيًا \\
\hline $25 \%$ & 5 & الثقافات الخارجية والعولمة \\
\hline
\end{tabular}


يتبين من جدول (9) أن أبرز التحديّات المستقبلية للتعلّم الإلكتروني في التدريس الجامعي من وجهة نظر الطلبة والمتعلقة بالآثار النفسية والاجتماعية والصحية والثقافية، جاءت التحديّات المرتبطة بالأمراض الصحية، والعُزلة، والإدمان في المراتب الأولى، في حين جاءت في مرتبة أدنى التحديّات المرتبطة بالدخول إلى مواقع غير مقبولة اجتماعيًا، والموقف من الثقافات الخارجية والعولمة. وقد تم التعبير عن هذه النتائج من خلال الرسم

البياني الموضح في الشكل (9).

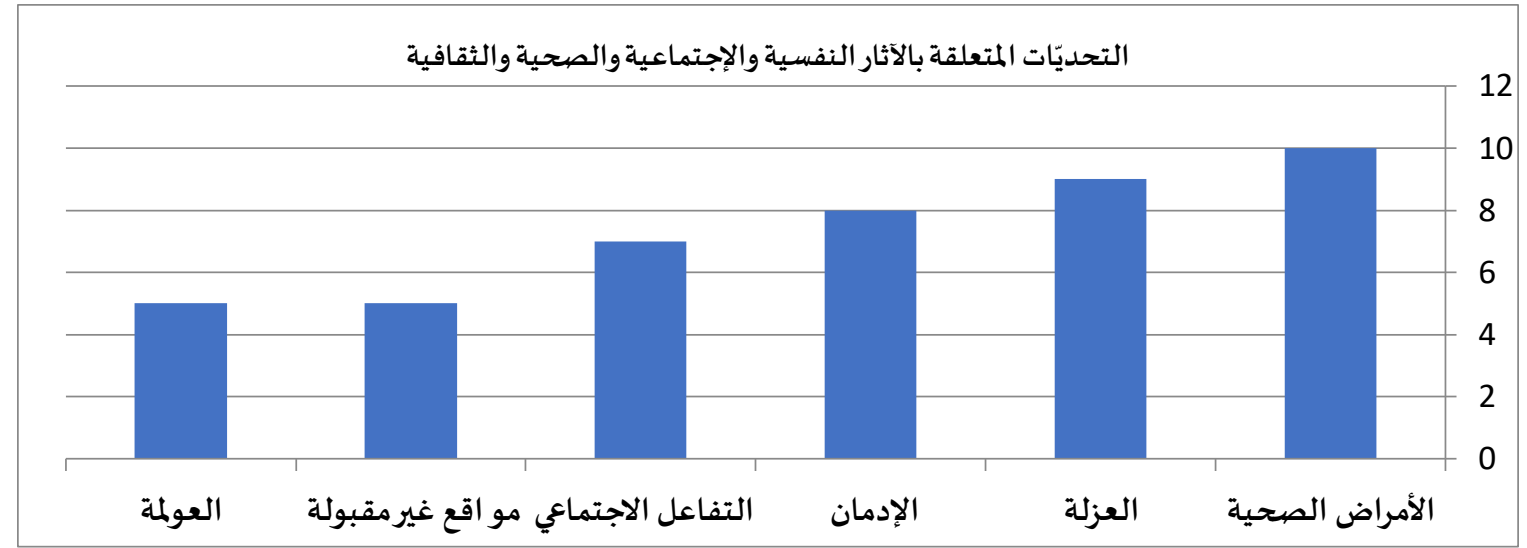

شكل (9): التحديّات المستقبلية للتعلّم الإلكتروني من وجهة نظر الطلبة المتعلقة بالآثار النفسية والاجتماعية والصحية والثقافية

جاءت نتائج تحليل إجابات الطلبة الخاصة بالتحديّات المستقبلية المترتبة على استخدام التعلّم الإلكتروني في التدريس الجامعي المتعلقة بالتحديّات التي تتعلق بالاتصال والتواصل وفق الجدات التدول رقم (10).

جدول (10): نتائج استبانات الطلبة حول التحديّات التي تتعلق بالاتصال والتواصل

\begin{tabular}{|c|c|c|}
\hline 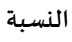 & التكرارات & التحديّات المتعلقة بالاتصال والتواصل \\
\hline \multicolumn{3}{|l|}{ 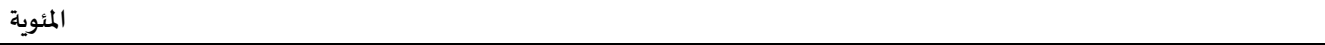 } \\
\hline $65 \%$ & 13 & مع الزملاء \\
\hline $25 \%$ & 5 & 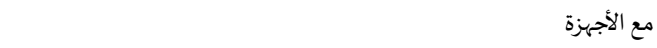 \\
\hline $20 \%$ & 4 & 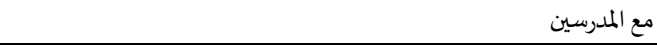 \\
\hline
\end{tabular}

يتبين من جدول (10) أن أبرز التحديّات المستقبلية للتعلّم الإلكتروني في التدريس الجامعي من وجهة نظر الطلبة والمتعلقة بالاتصال والتواصل، جاء التحدي المرتبط بالاتصال والتواصل مع الزملاء في المرتبة الأولى، بينما جاء في مرتبة دنيا الاتصال والتواصل مع المدرسين. وقد تم التعبير عن هذه النتائج من خلال الرسم البياني الموضح في الشكل (10).

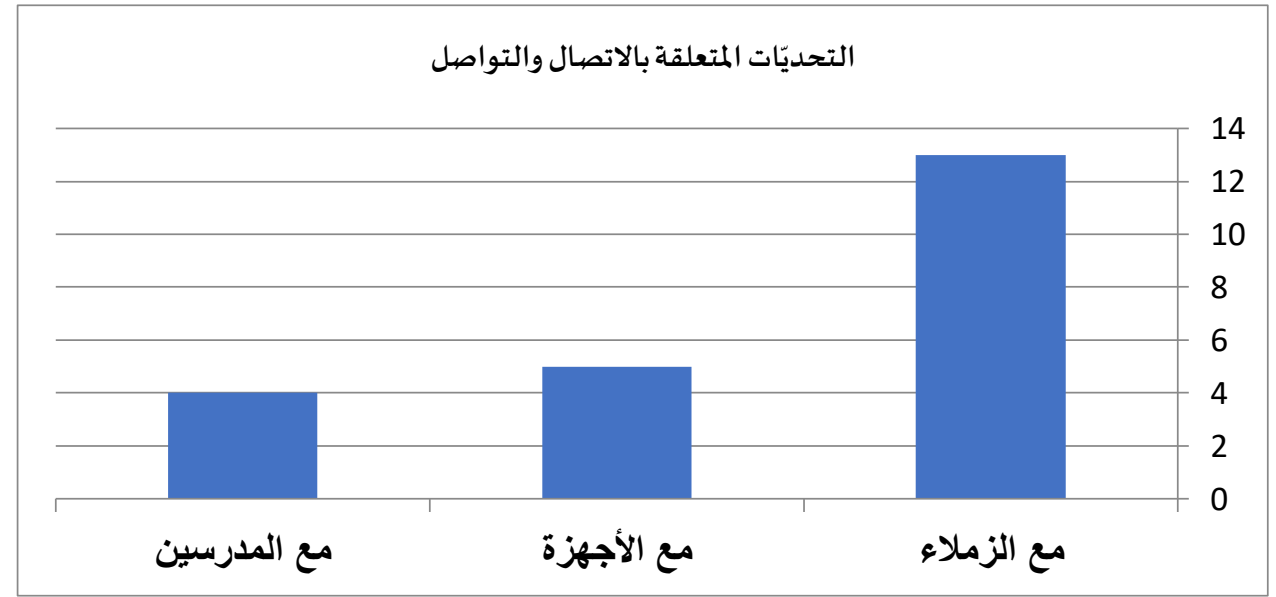

شكل (10): التحديّات المستقبلية للتعلّم الإلكتروني من وجهة نظر الطلبة المتعلقة بالاتصال والتواصل

جاءت نتائج تحليل إجابات الطلبة الخاصة بالتحديّات المستقبلية المترتبة على استخدام التعلّم الإلكتروني في التدريس الجامعي المتعلقة

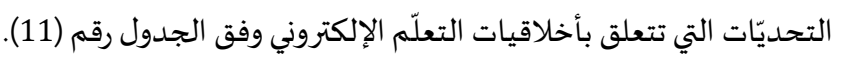


جدول (11): نتائج استبانات الطلبة حول التحديّات التي تتعلق بأخلاقيات التعلّم الإلكتروني

\begin{tabular}{|c|c|c|}
\hline المئوية & 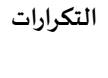 & التحديّات المتعلقة بأخلاقيات التعلّم الالكتروني \\
\hline $85 \%$ & 17 & الأمانة العلمية والنسخ الأعمى \\
\hline $50 \%$ & 10 & الخصوصيّة \\
\hline $30 \%$ & 6 & نشر الفيروسات \\
\hline $30 \%$ & 6 & 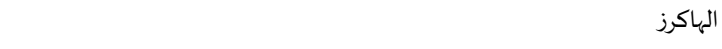 \\
\hline $25 \%$ & 5 & 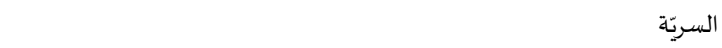 \\
\hline $15 \%$ & 3 & 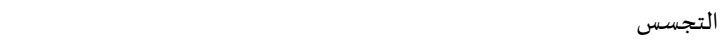 \\
\hline $5 \%$ & 1 & 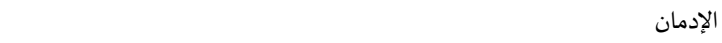 \\
\hline
\end{tabular}

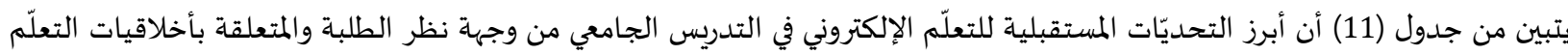

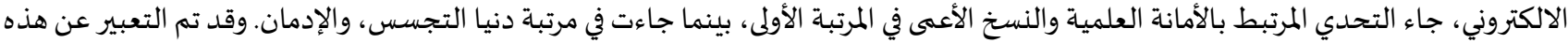

النتائج من خلال الرسم البياني الموضح في الشكل (11).

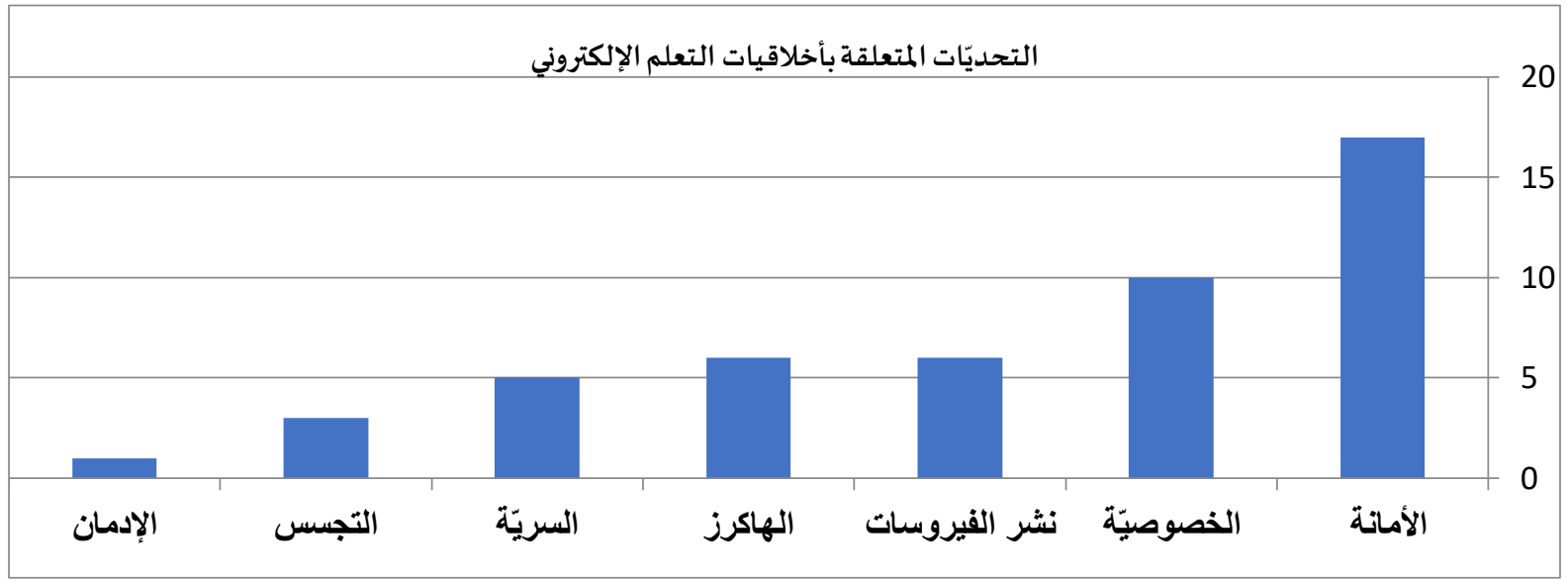

شكل (11): التحديّات المستقبلية للتعلّم الإلكتروني من وجهة نظر الطلبة المتعلقة بأخلاقيات التعلّم الإلكتروني

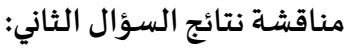

فيما يتعلق بإجابات الطلبة حول التحديّات المستقبلية للتعلّم الإلكتروني في التدريس الجامعي المتعلقة بالثقافة التكنولوجية، يُلاحظ أن أعلى

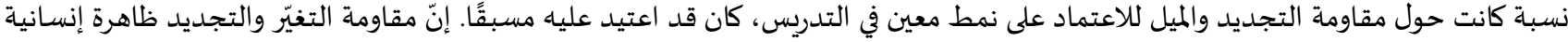

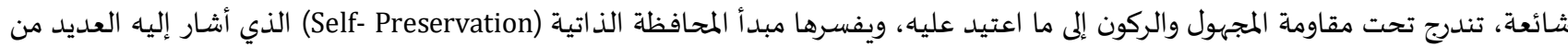

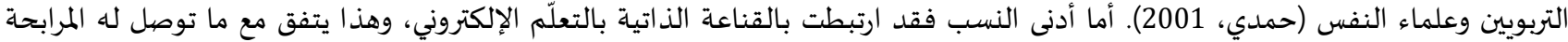

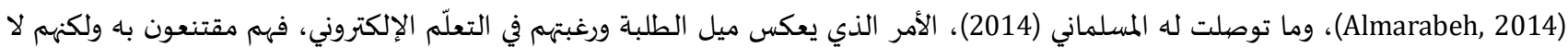

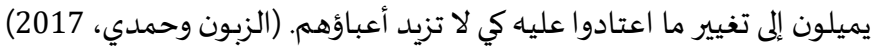

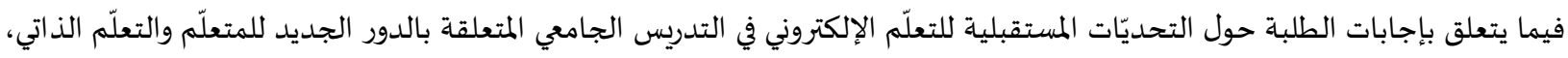

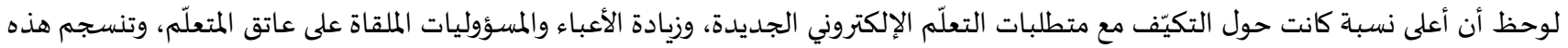

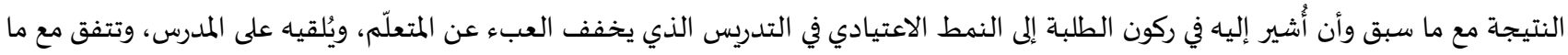

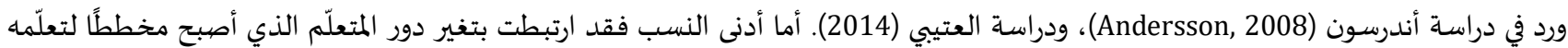

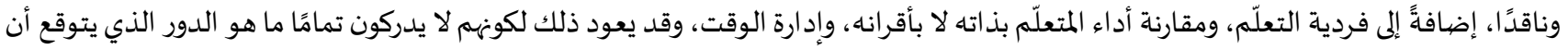

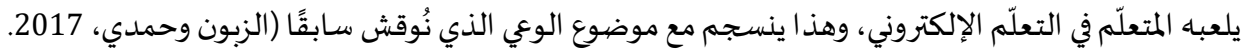

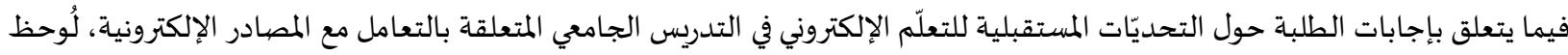

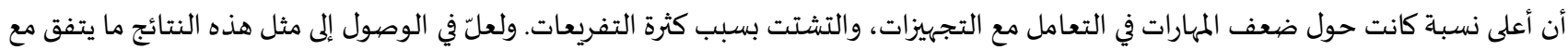

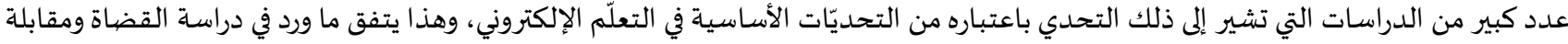

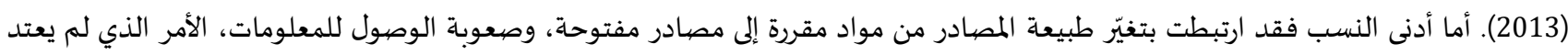

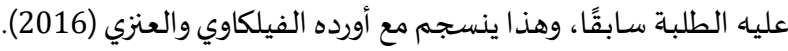


فيما يتعلق بإجابات الطلبة حول التحديّات المستقبلية للتعلّم الإلكتروني في التدريس الجامعي المتعلقة بالآثار النفسية والاجتماعية والصحية

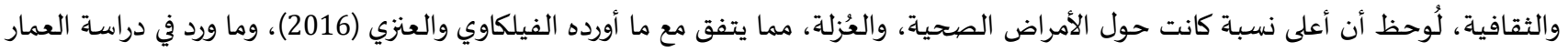

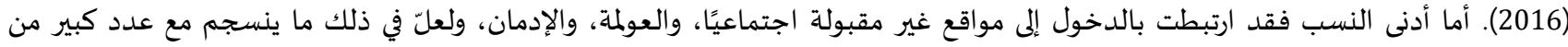
الدراسات التي أشـارت إلى مثل هذه النتيجة، ومنها دراسة أبو زيد (2011)، ودراسة العمار العمار (2016).

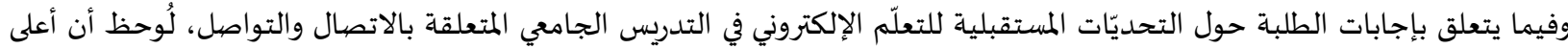
ذسبة كانت تلك المتعلقة بالاتصال والتواصل مع الزملاء. أما أدنى النسب فقد ارتبطت بالاتصال والتواصل مع المدرسين، ولعلّ في التوصل إلى مثل هذه

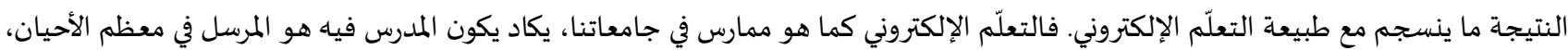

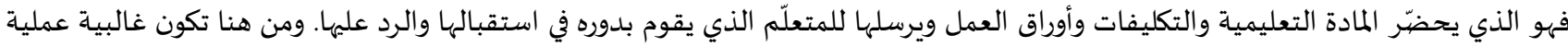
التواصل هي فيما يحدث من تفاعل بين المتعلّم والمدرس بشكل خاص. وهذواص وهذه النتيجة تتفق مع ما ورد في دراسة الزبون وحمدي (2018)، ودراسة راسبوبفيك وآخرون (Raspopvic, et al., 2016) ، ودراسـة كيبرتشي وآخرون (Kebritchi, et al., 2017).

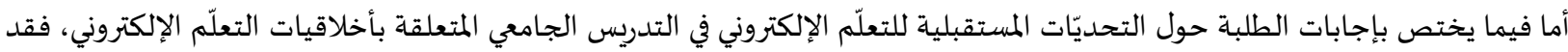

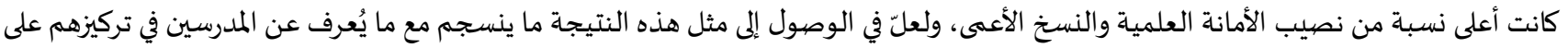

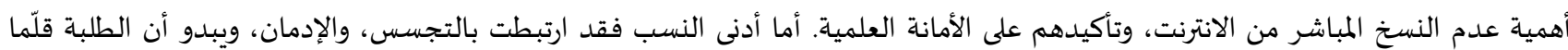
يُدمنون على استخد ام الانترنت في مجال التعلّم، بينما يختلف ذلك الأمر في المجالات الأخرى كالترفياه واللعب مثلًا (Al-Zahrani, 2015).

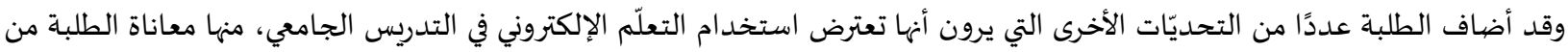

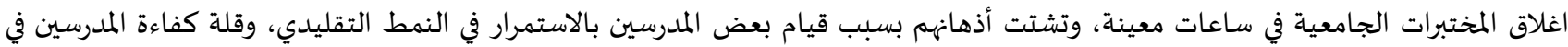

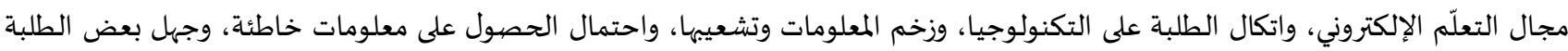

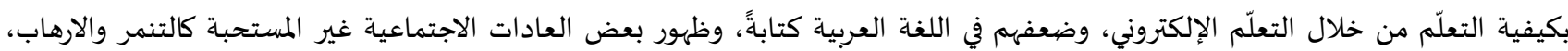

وضعف العلاقات الاجتماعية، وهذا يتفق ما أوردته العمار في دراستها (2016).

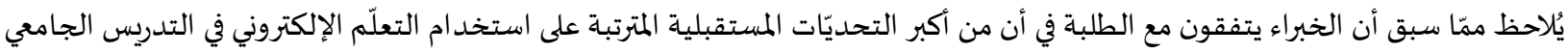

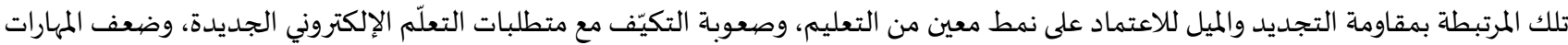

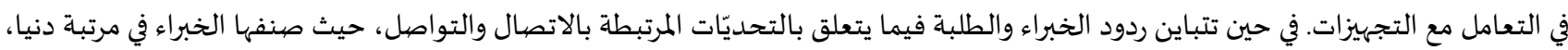
فيما وضعها الطلبة في مرتبة أعلى. وقد أجمع الطرفان على وجود آثار نفسية واجتماعية واخلاقية وثقافية وصحية تترتب على تبني التعلّم الإلكتروني في النظام التربوي.

3.4 التوصيات والمقترحات: تأسيسًا على ما سبق فيما يأتي عرض لعدود من المعرحات: التوصيات والمقترحات:

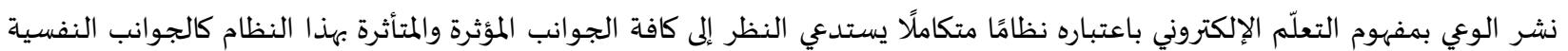
والاجتماعية والفكرية والصحية والأخلاقية المرتبطة بثقافة المجتمع وقيمارئ. توعية المدرسين وطلبتهم بأدوارهم المستقبلية الجديدة المتوقع أن يزاولوها في ظل نظام التعلّم الإلكتروني وتدريبهم على تلك الأدوار. التبصير بالقضايا الناتجة عن التعلّم الإلكتروني والمتعلقة بالآثار الإنسانية والأخلاقية وأثرها على المجتمع. تدريب المدرسين وطلبتهم على كيفية الوقوع على المعلومات واختيارها وتنقيحها ونقدها واستخد امها استخدامًا سليمًا. التركيز على تدريب المدرسين وطلبتهم على كيفية التعامل مع التجهيزات التقنية كونها أدوات المستقبل. العمل على إيجاد نظام حوافز جديد يسجل فياء كل من المدرس والمتعلم إبداعاتهما وابتكاراتهما في مجال التعلّم الإلكتروني.

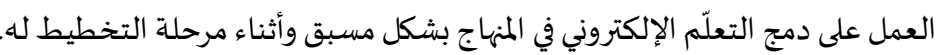
الاعتماد على الأجهزة الذكية التي بين أيدي الطلبة، والتخفف من التوسع في إنشاء مختبرات الحاسوب والانترنت. تطوير البيئة الملائمة للتعلّم الإلكتروني بما تشمله من متطلبات فنية ووظيفية ومادية. الاعتماد مبدئيًا على التعلّم المدمج الذي يعتبر نقله مرحلية في مزجاه بين النمط الاعتيادي والإلكتروني المحدّث، كما يمكن استخدام أسلوب فريق

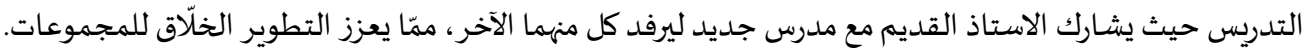

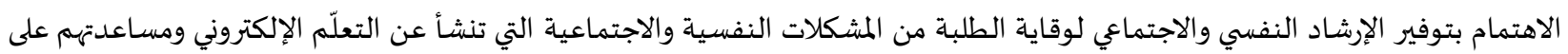


• العمل على توفير الحماية الكافية للمعلومات والحفاظ على خصوصيتها وسريتها وحمايتها من السرقات والاختراقات، وحجب المواقع غير المناسبة

والدعايات، والتأكد من مصداقية المعايه المعلومات في ظل سرعة انتشارها. • إجراء المزيد من البحوث والدراسات المستقبلية الرائدة في مجالات التعلّم الإلكتروني والآثار المترتبة عليه.

إجراء المزيد من الدراسات الهادفة إلى رسم الخطط وتوصيف الإجراءات اللازمة لبناء استراتيجيات حديثة لمواجهة تلك التحديّات الناشئة عن

استخدام نظام التعلّم الإلكتروني في التدريس الجامعي.

كلمة أخيرة:

لعلّ أكثر المهمات تحديَّا للقائمين على أمور التربية، تكمن في العمل على كيفية جذب المدرسين والطلبة الجامعيين إلى استخدام التعلّم

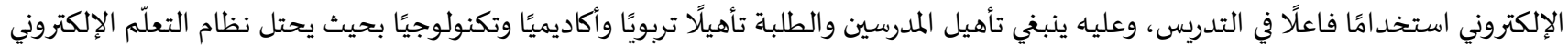

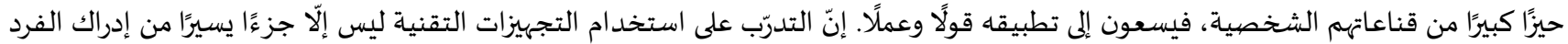

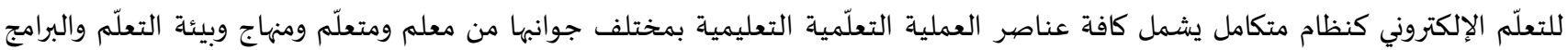
والأجهزة التقنية التي تؤثر وتتأثر بالجوانب الفكرية والثقافية والصحية والنفسية والأخلاقية والاجتماعية وطرق الاتصال والتواصل.

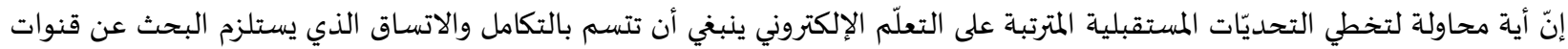

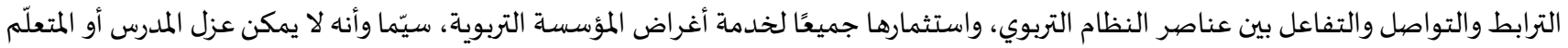

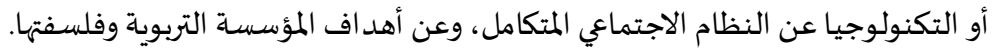

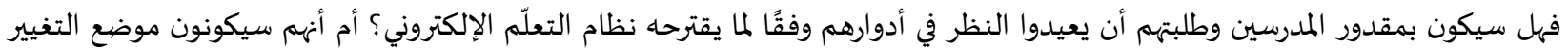

المفروض عليهم؟!!

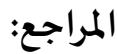

أولاً: المراجع العربية:

1. حمدي، نرجس (2001). نحو نموذج تكنولوجي معاصر لإعداد عضو هيئة التدريس الجامعي في مجال تكنولوجيا المعلومات. دراسات (الجامعة الأردنية): 82(2): 502-521.

2. حمدي، نرجس والبلوي، خليل (2011). درجة استعداد المعلمين في الأردن لمسايرة التحديّات المستقبلية المترتبة على استخدام تكنولوجيا

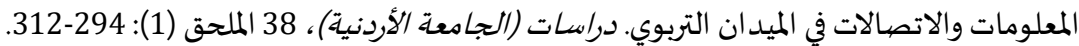
3. الحوامدة، محمد (2011). معوقات استخدام التعلّم الإلكتروني من وجهة نظر أعضياء الهيئة التدريسية في جامعة البلقاء التطبيقية. مجلة جامعة دمشق: $27(1)$ و(2): 803.

4. الزبون، مأمون وحمدي، نرجس (2018). أثر التدريس باستخدام نظام المقررات (مودل) في تحصيل طلبة الجامعة الأردنية بمادة مهارات

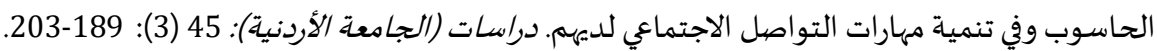
5. الزبون، مأمون وحمدي، نرجس (2017). أثر استخدام نظام مودل (Moodle) في تنمية مهارة التعلّم الذاتي لدى طلبة مادة مهارات الحاسوب في

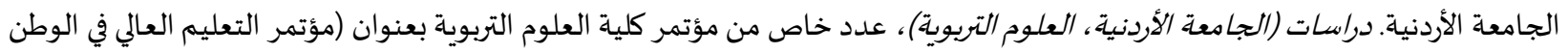
العربي).

6. أبو زيد، أحمد (2011). سوء استخدام الإنترنت وعلاقته بالضعف والمهارات الاجتماعية. مجلة دراسات عبربية في علم النفس: 10(1): 155-213. 7. 8. سليمان، هدى (2014). التحديّات الاجتماعية في الوطن العربي في الألفية (العقد الجديد). ورقة عمل مقدماسة إلى مؤتمر الحماية الاجتماعية والتنمية، جامعة نايف العبرية للعلوم الأمنية.

9. العتيبى، ضرار عبد الحميد التوم (2014). المعوقات الإدارية والتنظيمية للتعلم الإلكتروني: دراسة تطبيقية جامعة الملك خالد. مجلة العلوم الإد/رية: جامعة علدن - كلية العلوم الإدارية: $4(9)$ (9): 10. العمار، أمل (2016). التنمر الإلكتروني وعلاقتاه بإدمان الإنترنت في ضوء بعض إعض المتغيرات الديموغرافيه لدى طلاب وطالبات التعليم التطبيقي

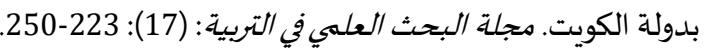

11. الفيلكاوي، أحمد والعنزي، عبد العزيز (2016). موسوعة تكنولوجيا التعليم - الموسوعة التكنولوجية التفاعلية. طبعة تفاعلية عبر الانترنت.

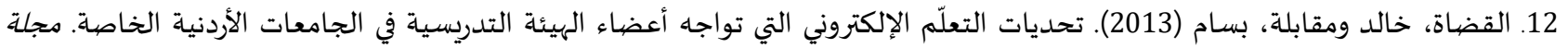
المنارة: 19 (3): 213-254. 
13. المسلماني، ليمياء (2014). التعليم والمواطنة الرقمياة: رؤية مقترحة. عالم التربية، المؤسسة العربية للاستشارات العلمية وتنمية الموارد البشسية:

.94-15:(47)15

ثانياً: المراجع الأجنبية:

1. Almarabeh, T. (2014). Student's Perceptions of e-learning of the University of Jordan. International Journal of Engineering and Technology, 9(3): 31-35.

2. Al-Zahrani, A. (2015). Toward Digital Citizenship: Examining Factors Affecting Participation and Involvement in the Internet Society among Higher Education Students. International Education Studies, 8(12): $2013-217$. https://doi.org/10.5539/ies.v8n12p203

3. Andersson, A. (2008). Seven major challenges for e-learning in developing countries: Case study. International Journal of Education and Development using Information and Communication Technology (IJEDICT), 4 (3): 45-62.

4. Fadde, P. \& Vu, P. (2013). Blended Online Learning: Benefits, Challenges, and Misconception. Blended Online Learning, Southern Illinois University Carbondale.

5. Hemant, R., Rajiv \& Manohar, L. (2014). E-Leaning: Issues and Challenges. International Journal of Computer Applications. 97 (5): 20-24.

6. Islam, N., Beer, M. \& Slack, F. (2015). e-Learning Challenges Faced by Academics in Higher Education: A literature Review. Journal of Education and Training Studies, 3 (5): 102-112. https://doi.org/10.11114/jets.v3i5.947

7. Kebritchi, M., Angie, A. \& Santiague, L. (2017). Issues and Challenges for Teaching Successful Online Courses in Higher Education: A Literature Review. Journal of Educational Technology Systems, 46(1): 4-29. https://doi.org/10.1177/0047239516661713

8. Mapuva, J. (2009). Confronting challenges to e-learning in Higher Education Institutions. International Journal of Education and Development using Information and Communication Technology (IJEDICT), 5 (3): 101-114.

9. Mashhour, A. \& Saleh, Z. (2010). Evaluating e-learning in Jordanian Institutions: Why Is It Lagging? Quarterly Review of Distance Education, 11 (4): 269-279.

10. Newman, F. (2000). The Future Project: Policy for Higher Education in a Changing World "Saving Higher Education's Soul”. Retrieved in 12/2/2019 from: www.futuresproject.org

11. Qureshi, I., Ilyas, K., Robina, Y. \& Whitty, M. (2012). Challenges of implementing e-learning in a Pakistani university. Knowledge Management \& e-Learning: An International Journal, 4 (3): 310- 324. https://doi.org/10.34105/j.kmel.2012.04.025

12. Raspopvic, M., Cvetanovic, S. \& Jankulovic, A. (2016). Challenges of Transitioning to an e-learning System with Learning Objects Capabilities. International Review of Research in Open and Distributed Learning, 17 (1): 123-147. https://doi.org/10.19173/irrodl.v17i1.2172 


\title{
The future challenges entailed by the application of electronic learning in the university instruction
}

\section{Narjes Abdul Qadir Hamdi}

Professor, Curriculum and Instruction Department, College of Educational Sciences, University of Jordan, Jordan narjeshamdi@yahoo.com

\author{
Received : 29/6/2021 Revised : 16/7/2021 Accepted : 24/8/2021 DOI : https://doi.org/10.31559/EPS2021.10.3.9
}

Abstract: This study described and analyzed the responses of a selected sample of experts and students in relation to the future challenges that might arise from the application of e-Learning in university instruction. Seventeen instructors and twenty students participated in two open-ended questionnaires. The questions consisted of a number of divisions: pertaining to instructors, students, curriculum, software and hardware use, and the educational system. The study examined the psychological, sociological, moral, cultural, health effects of the application of e-Learning. Based on the instructors' responses, the results of the study pointed out their shortage of awareness and lack of training when it comes to technological education among the main challenges they faced with a percentage (65\%), the high cost of e-Learning (65\%) in addition to the narrow understanding of the changing roles of educators and students as another important challenge (42\%), the difficulty of designing circular (35\%), lack of clear policies, and shortage of awareness of the concept of a system were also identified as important points (35\%). As for the students' responses, resistance to adopting new technology (55\%), lack of skills for using hardware and software were among the challenges they identified (55\%), and lack of coping with changing roles (40\%). Both instructors and students pointed out a number of psychological, sociological, cultural, and health effects of using e-Learning. The study recommended the importance of spreading awareness of the concept of e-Learning as a holistic system and called for more studies to come up with plans for building new strategies to encounter the challenges resulting from using eLearning in the university instruction.

\section{Keywords: e-Learning; Future Challenges; university instruction.}

\section{References:}

1. Al'mar, Aml (2016). Altnmr Alelktrwny W'laqth Bedman Alentrnt Fy Dw' B'd Almtghyrat Aldymwghrafyh Lda Tlab Wtalbat Alt'eym Alttbyqy Bdwlh Alkwyt. Mjlt Albhth Al'lmy Fy Altrbyh: (17): 250-223.

2. Al'tyba, Drar 'bd Alhmyd Altwm (2014). Alm'wqat Aledaryh Waltnzymyh Llt'm Alelktrwny: Drash Ttbyqyh Jam't Almlk Khald. Mjlt Al'lwm Aledaryh: Jam't 'dn - Klyth Al'lwm Aledaryh: 4(9): 9-47.

3. Alfylkawy, Ahmd Wal'nzy, 'bd Al'zyz (2016). Mwsw't Tknwlwjya Alt'lym - Almwsw'h

4. Hmdy, Nrjs (2001). Nhw Nmwdj Tknwlwjy M'asr Le'dad 'dw Hy't Altdrys Aljam'y Fy Mjal Tknwlwjya Alm'lwmat. Drasat (Aljam'h Alardnyh): 82(2): 521-502.

5. Hmdy, Nrjs Walblwy, Khlyl (2011). Drjt Ast'dad Alm'lmyn Fy Alardn Lmsayrh Althdyat Almstqblyh Almtrtbh 'la Astkhdam Tknwlwjya Alm'lwmat Walatsalat Fy Almydan Altrbwy. Drasat (Aljam'h Alardnyh), 38 Almlhq (1): 312-294.

6. Alhwamdh, Mhmd (2011). M'wqat Astkhdam Alt'lm Alelktrwny Mn Wjht Nzr A'da' Alhy'h Altdrysyh Fy Jam't Alblqa' Alttbyqyh. Mjlt Jam't Dmshq: 27(1) W(2): 803.

7. Almslmany, Lymya' (2014). Alt'lym Walmwatnh Alrqmyh: R'yh Mqtrhh. 'alm Altrbyh, Alm'ssh Al'rbyh Llastsharat Al'lmyh Wtnmyh Almward Albshryh: 15(47): 94-15.

8. Alqdah, Khald Wmqablh, Bsam (2013). Thdyat Alt'lm Alelktrwny Alty Twajh A'da' Alhy'h Altdrysyh Fy Aljam'at Alardnyh Alkhash. Mjlt Almnarh: 19 (3): 254-213.

9. Alslyty, Fras (2015). Astratyjyat Altdrys Alm'asrh. T1, Erbd, 'alm Alktb Alhdyth.

10. Slyman, Hda (2014). Althdyat Alajtma'yh Fy Alwtn Al'rby Fy Alalfyh (Al'qd Aljdyd). Wrqt 'ml Mqdmh Ela M'tmr Alhmayh Alajtma'yh Waltnmyh, Jam't Nayf Al'rbyh Ll'lwm Alamnyh. 
11. Alzbwn, Mamwn Whmdy, Nrjs (2017). Athr Astkhdam Nzam Mwdl (Moodle) Fy Tnmyt Mhart Alt'lm Aldaty Lda Tlbt Madt Mharat Alhaswb Fy Aljam'h Alardnyh. Drasat (Aljam'h Alardnyh, Al'lwm Altrbwyh), 'dd Khas Mn M'tmr Klyh Al'lwm Altrbwyh B'nwan (M'tmr Alt'lym Al'aly Fy Alwtn Al'rby).

12. Alzbwn, Mamwn Whmdy, Nrjs (2018). Athr Altdrys Bastkhdam Nzam Almqrrat (Mwdl) Fy Thsyl Tlbt Aljam'h Alardnyh Bmadt Mharat Alhaswb Wfy Tnmyt Mharat Altwasl Alajtma'y Ldyhm. Drasat (Aljam'h Alardnyh): (3) 45: 203-189.

13. Abw Zyd, Ahmd (2011). Sw' Astkhdam Alentrnt W'laqth Bald'f Walmharat Alajtma'yh. Mjlt Drasat 'rbyh Fy 'Im Alnfs: 10(1): 213-155. 